\title{
Crisoles y moldes en Los Nogales: Estudio tecnológico de cerámicas metalúrgicas del Período Tardío en el valle del Aconcagua, Chile Central
}

\section{Crucibles and moulds from Los Nogales: Technological study of technical ceramics from the Late Period in the Aconcagua Valley, Central Chile}

\author{
María Teresa Plaza Calonge1 (D) https://orcid.org/0000-0002-8533-2447

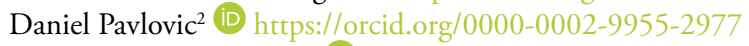 \\ Marcos Martinón-Torres ${ }^{3}$ (D) https://orcid.org/0000-0003-2124-2837 \\ ${ }^{1}$ Escuela de Antropología, Pontificia Universidad Católica de Chile, Santiago, CHILE. \\ Email: tereplazacalonge@gmail.com \\ ${ }^{2}$ Investigador CIEM-Aconcagua, CHILE. Email: daniel.pavlovic@gmail.com \\ ${ }^{3}$ Department of Archaeology, University of Cambridge, UNITED KINGDOM. \\ Email: m.martinon-torres@arch.cam.ac.uk
}

\section{Resumen}

La expansión del Tawantinsuyu en el valle del Aconcagua (Chile central) fue culturalmente mediada y evitando la coerción militar, lo que derivó en distintas formas de aceptación, resistencia y aculturación. En este contexto, son casi inexistentes los estudios que discutan cómo este proceso se manifestó en la tecnología metalúrgica del Período Tardío (ca. 1400-1530 DC). Presentamos los resultados del estudio tecnológico sobre un conjunto de crisoles y moldes encontrados en el valle del Aconcagua y asociados a piezas metálicas hechas en base a cobre, utilizando microscopía óptica, petrografía, SEM-EDS, XRD y FTIR. Nuestros resultados indican que las materias primas utilizadas fueron rocas ígneas obtenidas de depósitos probablemente locales, mezcladas con pequeñas cantidades de arcillas tipo esmectitas-montmorillonitas. En el caso de los moldes, estos además contenían hueso molido como antiplástico. Todas las cerámicas fueron cubiertas con una pasta de hueso puro para mejorar su refractariedad. Las temperaturas de cocción se estimaron entre 800 y $850{ }^{\circ} \mathrm{C}$ para los moldes y superior a los $900{ }^{\circ} \mathrm{C}$ para los crisoles. La morfología y tecnología utilizada sugieren que una tradición tecnológica originada en el Noroeste Argentino fue introducida al valle del Aconcagua y aceptada por ciertas comunidades locales durante la expansión del Tawantinsuyu.

Palabras clave: metalurgia, Período Tardío, petrografía, SEM-EDS, XRD. 


\begin{abstract}
The spread of the Tawantinsuyu in the Aconcagua Valley (Central Chile) is thought to have been culturally mediated, avoiding military coercion, and thus leading to different forms of cultural acceptance, resistance or hybridisation. However, very few studies have discussed how this process is reflected in the metallurgical production during the Late Period (ca. AD 14001530). The result of a technological study on a group of crucibles and moulds from Los Nogales (Aconcagua valley), using optical microscopy, petrography, SEM-EDS, XRD and FTIR is presented here. Results indicate that the raw materials used were local igneous rocks obtained from alluvial deposits, mixed with small amounts of smectite-montmorillonite clay. Moulds also contained bone ash as temper. Firing temperatures were estimated between $800-850{ }^{\circ} \mathrm{C}$ for moulds and above $900^{\circ} \mathrm{C}$ for crucibles. Their manufacture technology and morphology indicate that these technical ceramics were made following a technological tradition originated in northwest Argentina that was introduced to the Aconcagua valley during the expansion of the Tawantinsuyu, and accepted by local communities.
\end{abstract}

Keywords: metallurgy, Late Period, petrography, SEM-EDS, XRD.

Recibido: 21 abril 2020. Aceptado: 22 junio 2020 


\section{Introducción}

El interés del Tawantinsuyu por la industria minero-metalúrgica del Collasuyu se evidencia en los cambios que introduce a las tecnologías locales, especialmente en la reorganización del espacio y el incremento en la escala de producción, tanto en sitios mineros como metalúrgicos del norte de Chile y del Noroeste Argentino (en adelante, NOA) (Salazar y Salinas, 2008; Cantarutti, 2013; Figueroa-Larre et al., 2018; entre otros). Junto con estas evidencias, se observa un cruce de tecnologías, donde elementos tecnológicos que se asocian a ciertos lugares comienzan a aparecer fuera de su área de origen, sugiriendo que este control de la producción metalúrgica involucró la circulación de conocimientos, materiales y probablemente especialistas (Niemeyer, 1979; L. R. González, 2004; Zori et al., 2013; Plaza y Martinón-Torres, 2015; Zori, 2018). Dentro de este contexto destacan los crisoles de base perforada (Figura 1A), cerámicas que corresponden a un tipo de crisol que fue desarrollado en el NOA y cuyo uso fue extendido e implementado en otros sitios metalúrgicos de Chile y Argentina durante el Período Tardío (PT) en el contexto de la expansión del Tawantisuyu (Niemeyer, 1979, 1986; L. R. González, 1997, 1998, 2002a, 2002b, 2004, 2010; L. R. González y Gluzman, 2009; Plaza y Martinón-Torres, 2015).

En este artículo presentamos en detalle los resultados del estudio tecnológico de un conjunto de crisoles de base perforada y moldes metalúrgicos encontrados en el valle del Aconcagua de Chile central, para discutir las decisiones tecnológicas utilizadas y el posible significado de su presencia en dicha área. Estas cerámicas técnicas o metalúrgicas ${ }^{1}$ corresponden no solo a las evidencias más meridionales de este tipo, sino que se encontraron en un contexto poco común para estos materiales: una ocupación doméstica del PT sin intervención incaica. Asimismo, los análisis revelaron que estas cerámicas técnicas no fueron utilizadas, siendo esta la primera caracterización completa de este tipo de piezas sin huellas de uso, permitiendo una comprensión más detallada de su manufactura. En este artículo profundizamos los resultados previamente publicados (Plaza y Martinón-Torres, 2015), incluyendo análisis inéditos realizados a estas cerámicas, con el fin de aportar al estudio de las cerámicas técnicas en Sudamérica y entregar información que permita comparar e integrar la investigación de estas piezas a nivel regional.

1 En este artículo utilizaremos el término cerámica metalúrgica o cerámica técnica, evitando usar el término "refractario", ya que muchas de estas cerámicas, si bien son utilizadas en actividades que involucran altas temperaturas, no necesariamente se definen como refractarias, entendido como "que resiste la acción del fuego sin alterarse” (Diccionario de la Real Academia Española, versión online). 


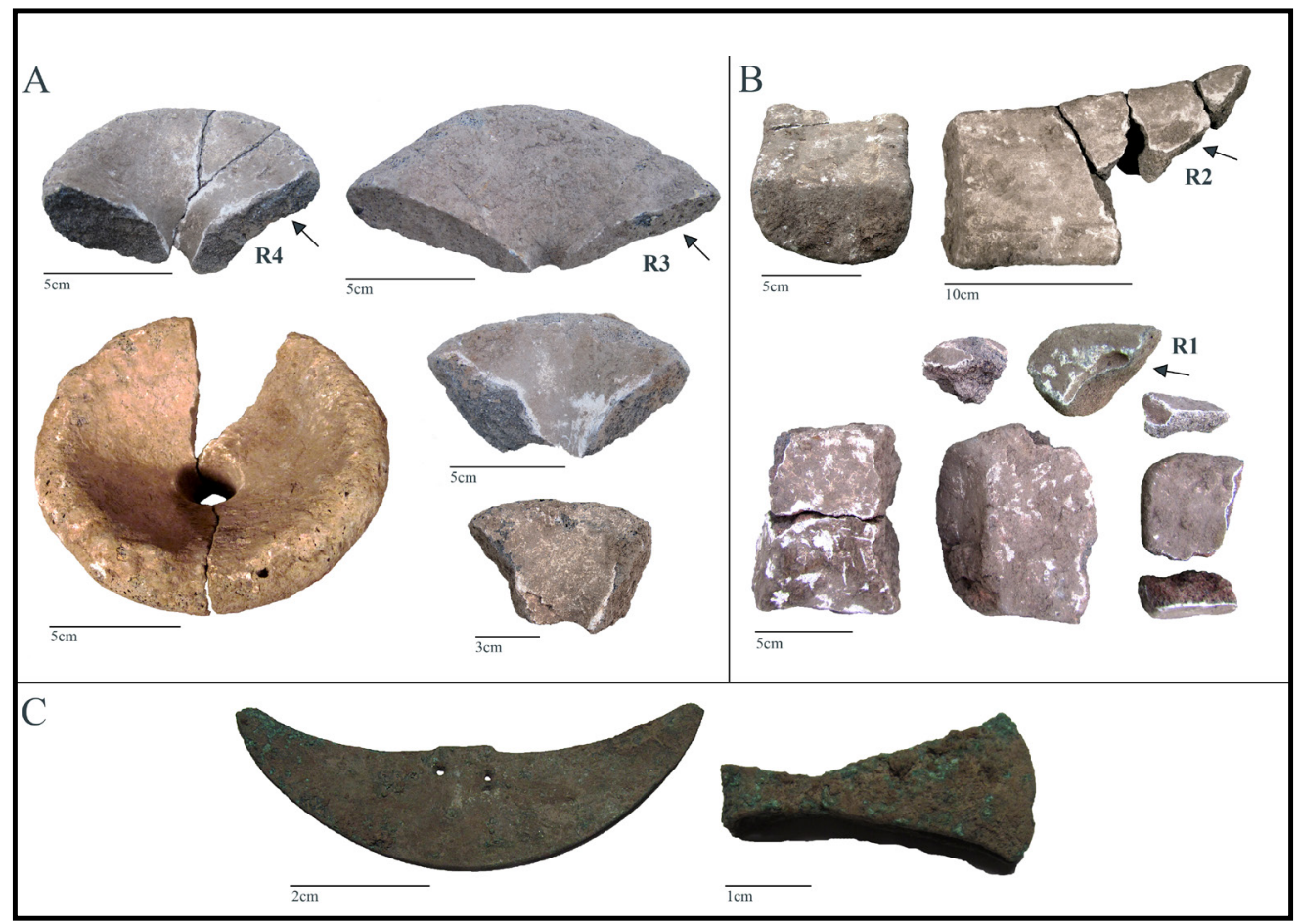

Figura 1. Cerámicas metalúrgicas y objetos metálicos encontrados en Los Nogales. A) Crisoles con agujeros en la base, B) moldes, y C) piezas de metal. Las flechas señalan las secciones analizadas.

\section{Antecedentes: el uso de metales en el valle de Aconcagua}

Durante el Período Intermedio Tardío (PIT; ca. 900-1400 DC) el uso y la producción de metales en Chile central ${ }^{2}$ se focalizó en sitios de la cultura Aconcagua, acotada principalmente al valle Maipo-Mapocho. En dicho valle se han reportado alrededor de 23 piezas de cobre (cuentas, láminas, anzuelos y aros), además de restos de producción metalúrgica como fragmentos de mineral y pepitas de cobre, escoria, cerámica con escoria adherida y cuatro posibles moldes (Campbell y Latorre, 2003; Plaza, 2010). Durante el PIT, los artefactos de metal se encuentran asociados a sitios funerarios, mientras que las evidencias de producción metalúrgica aparecen en sitios habitacionales (Plaza, 2010). Dada la escasa cantidad de evidencias de producción metalúrgica y el hecho de que aparezcan en sitios habitacionales, Latorre (2006) sugiere para el PIT una producción de metales a pequeña escala basada en eventos ocasionales. Por su parte, no existen referencias hasta ahora de trabajo en metal para el PIT en el valle del Aconcagua ${ }^{3}$ (Rivas y Ocampo, 1997; Campbell y Latorre, 2003; Plaza, 2010).

2 De las tres cuencas que conforman Chile Central, hemos incluimos en este artículo las evidencias de la región Metropolitana (cuenca Maipo-Mapocho) y región de Valparaíso (cuenca del Aconcagua), quedando excluida la región del Libertador Bernardo O'Higgins (cuenca del Cachapoal).

3 Se han descrito hallazgos de anzuelos de cobre y adornos o miniaturas de metal asociados a un sitio de la cultura Aconcagua en Quintay (Rivas y Ocampo, 1997). Sin embargo por su ubicación $33 \mathrm{~km}$ al sur de la desembocadura del río Aconcagua y asociados a pequeñas cuencas de la cordillera de la Costa, es posible que esté más asociado a las dinámicas de la cuenca del Maipo-Mapocho que a las del Aconcagua. 
Este panorama cambia drásticamente durante el PT (ca. 1400-1530 DC), cuando se registran en total cerca de 109 objetos de metal: 47 en el valle Maipo-Mapocho y 62 en el valle del Aconcagua (Tabla 1). En este último, las piezas se distribuyen en 10 sitios, de los cuales seis corresponden a sitios incaicos que concentran un $90 \%(\mathrm{n}=56)$ de los objetos metálicos (Plaza,

Tabla 1. Resumen de los sitios del valle del Aconcagua y Maipo-Mapocho con objetos metálicos o evidencias de producción metalúrgica del Período Tardío.

\begin{tabular}{|c|c|c|c|c|c|c|c|}
\hline Valle & Sitio & $\begin{array}{c}\text { No de } \\
\text { objetos } \\
\text { de } \\
\text { metal }\end{array}$ & $\%$ & $\begin{array}{l}\text { Evidencias de } \\
\text { producción } \\
\text { metalúrgica }\end{array}$ & $\begin{array}{l}\text { Funcionalidad } \\
\text { de los sitios }\end{array}$ & $\begin{array}{l}\text { Asociación } \\
\text { cultural }\end{array}$ & Referencias \\
\hline \multirow{12}{*}{ 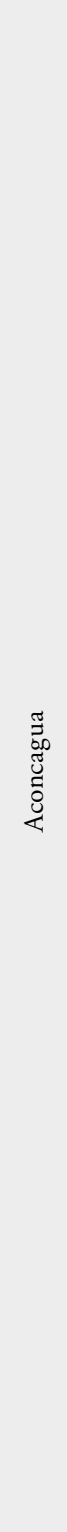 } & $\begin{array}{c}\text { Cerro } \\
\text { La Cruz }\end{array}$ & 44 & 71 & & $\begin{array}{c}\text { Centro } \\
\text { Ceremonial }\end{array}$ & Inca & $\begin{array}{l}\text { (Rodríguez } \\
\text { et al., 1993; } \\
\text { Martínez, } \\
\text { 2011, 2012) }\end{array}$ \\
\hline & $\begin{array}{c}\text { Cerro } \\
\text { Aconcagua }\end{array}$ & 5 & 8 & & $\begin{array}{l}\text { Adoratorio } \\
\text { de altura }\end{array}$ & Inca & $\begin{array}{c}\text { (Schobinger, } \\
\text { 1995; } \\
\text { Bárcena, } \\
\text { 2001; } \\
\text { Schobinger } \\
\text { et al., 2001) }\end{array}$ \\
\hline & $\begin{array}{l}\text { Los } \\
\text { Quillayes }\end{array}$ & 3 & 5 & & Funerario & Inca & $\begin{array}{c}\text { (Stehberg y } \\
\text { Sotomayor, } \\
\text { 1999) }\end{array}$ \\
\hline & $\begin{array}{l}\text { Estadio } \\
\text { Quillota }\end{array}$ & 3 & 5 & & Funerario & Inca & $\begin{array}{c}\text { (Gajardo- } \\
\text { Tobar y Silva, } \\
\text { 1970) }\end{array}$ \\
\hline & Los Nogales & 2 & 3 & $\begin{array}{c}\text { Crisoles } \\
\text { y moldes }\end{array}$ & $\begin{array}{l}\text { Habitacional } \\
\text { y funerario }\end{array}$ & Local del PT & $\begin{array}{l}\text { (Pavlovic, } \\
\text { 2010) }\end{array}$ \\
\hline & Carolina & 1 & 2 & & Funerario & Local del PT & $\begin{array}{c}\text { (Ávalos y } \\
\text { Saunier, com. } \\
\text { pers. 2009) }\end{array}$ \\
\hline & $\begin{array}{c}\text { Casa Blanca } \\
30\end{array}$ & 1 & 2 & & Habitacional & Local del PT & $\begin{array}{l}\text { (Pavlovic } \\
\text { et al., 2004) }\end{array}$ \\
\hline & Panquehue & 1 & 2 & & Hallazgo aislado & Indeterminado & $\begin{array}{l}\text { (Pavlovic } \\
\text { et al., 2004) }\end{array}$ \\
\hline & $\begin{array}{c}\text { Tambo Ojos } \\
\text { de Agua }\end{array}$ & 1 & 2 & & Tambo & Inca & $\begin{array}{l}\text { (Garceau } \\
\text { et al., 2010) }\end{array}$ \\
\hline & $\begin{array}{c}\text { Villa } \\
\text { Alemana- } \\
\text { El Sauce }\end{array}$ & 1 & 2 & & Hallazgo aislado & Indeterminado & $\begin{array}{c}\text { (Fonck, 1910; } \\
\text { Stehberg, } \\
1975)\end{array}$ \\
\hline & El Castillo & & & $\begin{array}{l}1 \text { Fragmento } \\
\text { de cerámica } \\
\text { con escoria } \\
\text { y posibles } \\
\text { escorias }\end{array}$ & $\begin{array}{l}\text { Tambo o centro } \\
\text { administrativo }\end{array}$ & Inca & $\begin{array}{l}\text { (Sánchez, } \\
\text { 2002) }\end{array}$ \\
\hline & Subtotal & 62 & 100 & & & & \\
\hline
\end{tabular}




\begin{tabular}{|c|c|c|c|c|c|c|c|}
\hline \multirow{10}{*}{ 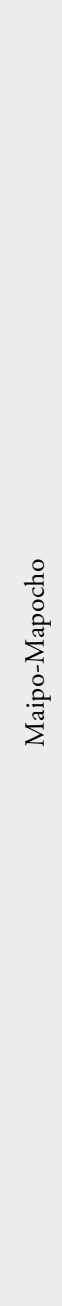 } & $\begin{array}{c}\text { Cementerio } \\
\text { La Reina }\end{array}$ & 19 & 40 & & Funerario & Inca & $\begin{array}{c}\text { (Mostny, } \\
1947)\end{array}$ \\
\hline & $\begin{array}{c}\text { San Agustín } \\
\text { de Tango }\end{array}$ & 8 & 17 & & Funerario & Indeterminado & $\begin{array}{l}\text { (Housse, } \\
\text { 1960; } \\
\text { Stehberg, } \\
1976)\end{array}$ \\
\hline & $\begin{array}{c}\text { Cerro } \\
\text { El Plomo }\end{array}$ & 6 & 13 & & $\begin{array}{l}\text { Adoratorio de } \\
\text { altura }\end{array}$ & Inca & $\begin{array}{c}\text { (Mostny, } \\
\text { 1959; Cabe- } \\
\text { za, 1986) }\end{array}$ \\
\hline & $\begin{array}{l}\text { La Aldea } \\
\text { El Peral }\end{array}$ & 6 & 13 & & Habitacional & Indeterminado & $\begin{array}{c}\text { (C. González, } \\
1998)\end{array}$ \\
\hline & $\begin{array}{l}\text { San José } \\
\text { de Maipo }\end{array}$ & 4 & 9 & & Funerario & Indeterminado & $\begin{array}{c}\text { (Ewbank, } \\
\text { 1855; Medi- } \\
\text { na, 1882; } \\
\text { Latcham, } \\
\text { 1928; } \\
\text { Stehberg, } \\
\text { 1975; Mayer, } \\
\text { 1986) }\end{array}$ \\
\hline & $\begin{array}{c}\text { Calle } \\
\text { Catedral }\end{array}$ & 1 & 2 & & Funerario & Indeterminado & $\begin{array}{l}\text { (Latcham, } \\
\text { 1928; } \\
\text { Stehberg, } \\
1975)\end{array}$ \\
\hline & El Coligüe & 1 & 2 & $\begin{array}{l}\text { Posibles } \\
\text { escorias }\end{array}$ & Habitacional & Local del PT & $\begin{array}{c}\text { (Durán et al., } \\
2000)\end{array}$ \\
\hline & $\begin{array}{l}\text { Las Bateas } \\
\text { Oriente }\end{array}$ & 1 & 2 & & Habitacional & Local del PT & $\begin{array}{c}\text { (Rodríguez } \\
\text { y González, } \\
2000)\end{array}$ \\
\hline & $\begin{array}{c}\text { Pucará } \\
\text { de Chena }\end{array}$ & 1 & 2 & & Fortaleza & Inca & $\begin{array}{c}\text { (Stehberg, } \\
1976,1977 \text { ) }\end{array}$ \\
\hline & Subtotal & 47 & 100 & & & & \\
\hline \multicolumn{2}{|c|}{$\begin{array}{l}\text { Total general } \\
\text { durante el PT }\end{array}$} & 109 & & & & & \\
\hline
\end{tabular}

Fuente: Modificado de Plaza, 2010. 


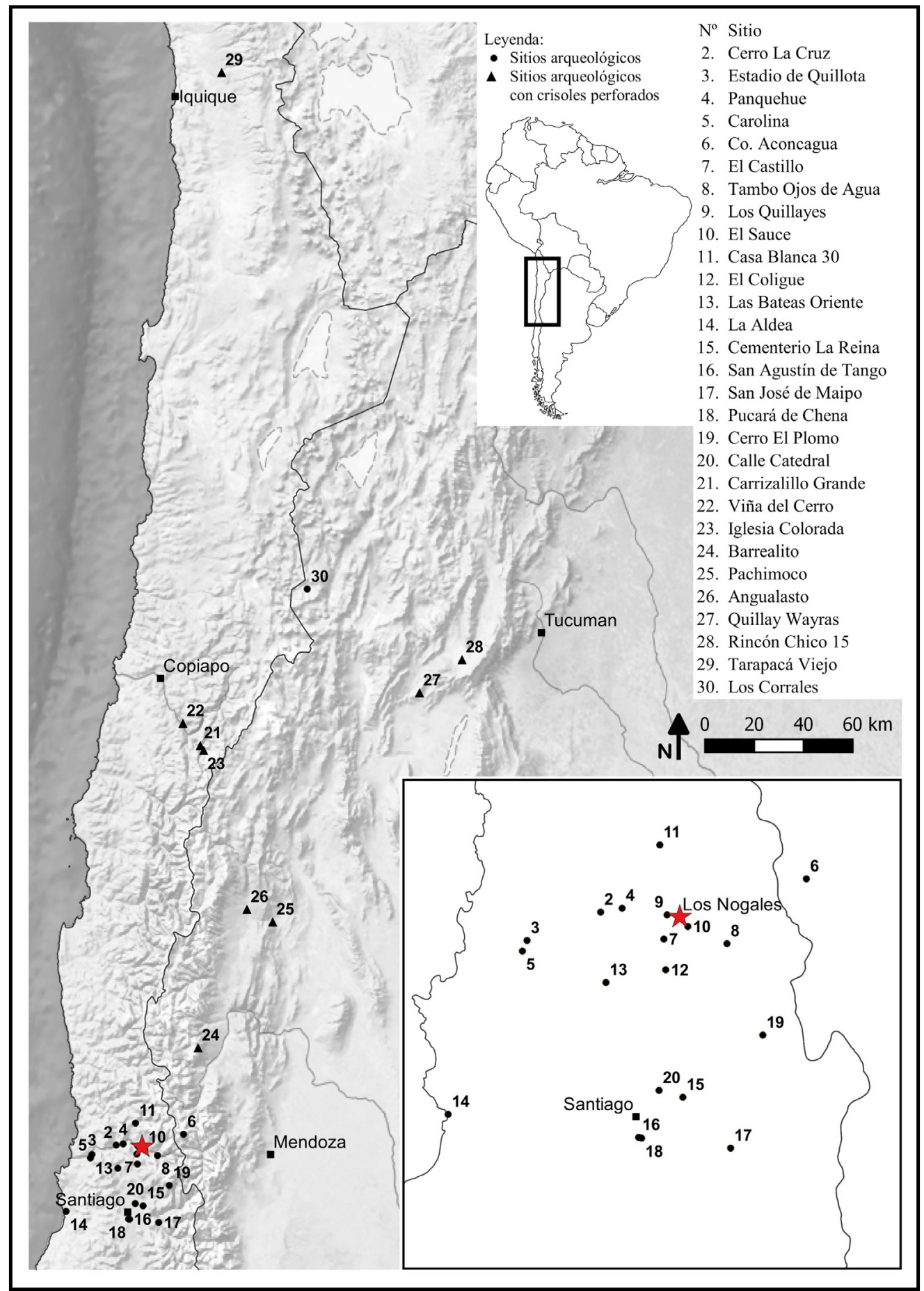

Figura 2. Mapa de los sitios mencionados en este artículo. 
2010, 2013). Si bien la cantidad de piezas es mayor para el PT, las evidencias de producción metalúrgica disminuyen significativamente, desapareciendo casi en su totalidad del valle del Maipo-Mapocho. Solo se reportan posibles escorias y un fragmento cerámico con escoria adherida en el sitio El Castillo, del valle del Aconcagua (Sánchez, 2002; Plaza, 2010, 2013); y posibles escorias en El Coligüe ${ }^{4}$ (Durán, Rodríguez y González, 2000). Tampoco se registran en Chile central asentamientos o evidencias asociadas a la explotación minera (Troncoso, Pavlovic, Acuto, Sánchez y González, 2012), lo cual sugiere que la mayor parte del metal y/o objetos presentes en el han llegado desde afuera.

A partir de estos antecedentes, los hallazgos del sitio Los Nogales ubicado en las proximidades de la ciudad de Los Andes destacan por su particularidad (Figura 1). Excavado en 2009, se rescataron 12 cerámicas que por sus características podrían relacionarse con operaciones metalúrgicas, un hallazgo inédito hasta ahora en Chile central. Como mencionamos, piezas similares se reportan en sitios incaicos con actividades metalúrgicas del NOA y norte de Chile (Figura 2) (Debenedetti, 1916; Niemeyer, 1979; Raffino et al., 1996; L. R. González, 1997, 2010; Zori et al., 2012). En este trabajo reportamos los estudios aplicados a estas cerámicas, los cuales permitieron determinar las materias primas utilizadas, temperaturas de cocción y grado de uso. Los resultados indican que efectivamente corresponden a un conjunto de crisoles y moldes pero sin huellas de uso, siendo hasta ahora la única oportunidad que se ha tenido de estudiar estas cerámicas metalúrgicas antes de ser utilizadas.

\section{El sitio}

Los Nogales se ubica en la localidad de San Esteban, en las proximidades de la ciudad de Los Andes, en una extensa terraza fluvial situada al norte del curso superior del río Aconcagua. El sitio se excavó en el marco de un salvataje arqueológico en el año 2009. Aunque las fechas radiocarbónicas y TL indican un uso continuo desde el PAT, ${ }^{5}$ las ocupaciones principales datan del PIT y el PT, con fechas de 1300-1400 DC, 1420-1488 DC y 1470-1640 DC (Figura 3 y Tabla 2) (Pavlovic, 2010). A pesar de la fecha colonial de 1640 DC, no se encontraron materiales históricos en el sitio. La ocupación del PT corresponde a un área doméstica con abundante concentración de materiales y un entierro aislado, aunque no se identificaron estructuras residenciales. La cerámica doméstica presenta tipos locales del PT como monócromos y rojo engobado, y cerámica propia de la Cultura Aconcagua del valle del Maipo-Mapocho, como Aconcagua salmón negro sobre salmón y Trícromo Engobado (Dávila, 2010). Las cerámicas metalúrgicas analizadas por los autores se encontraban dispersas en superficie, con excepción del crisol R3 (Figura 1A) que se rescató a 20-40 cm de profundidad (Pavlovic, 2010). Asociadas a un individuo inhumado se registraron dos piezas de metal: una pinza y una placa semilunar (Figura 1C). Los análisis de composición química indican que la placa semilunar fue hecha en bronce con $11 \%$ de estaño (Plaza y Martinón-Torres, 2015) y su diseño tiene características incaicas (Horta, 2008, 2016).

4 Lamentablemente, dichas escorias no se encontraron entre los materiales recuperados del sitio para estudiarlas en mayor profundidad.

5 Las fechas tempranas pertenecientes al PAT se asocian a un individuo hiperflectado que portaba un tembetá, y que también fue rescatado en el proceso de salvataje. 


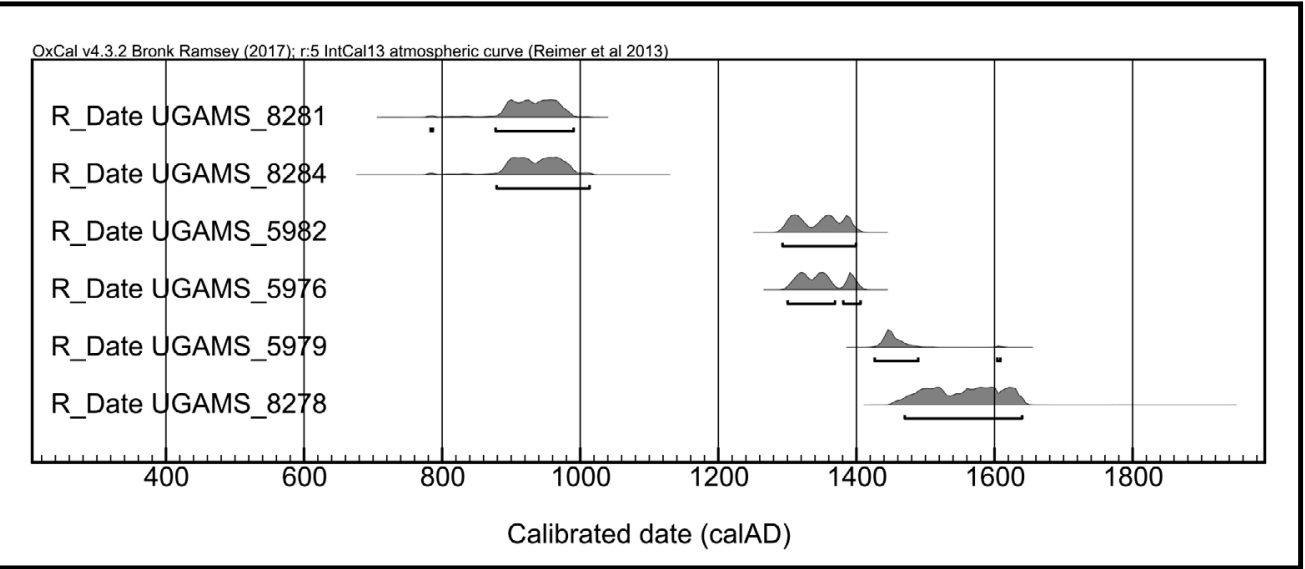

Figura 3. Fechados radiocarbónicos del sitio Los Nogales. Ver detalles en Tabla 2. Fechas obtenidas el año 2010 y recalibradas el ańo 2019 por OxCal v4.3.2 Bronk Ramsey (2017); r:5 IntCAl13 atmospheric curve (Reimer et al., 2013).

Tabla 2. Fechas radiocarbónicas (A) y de termoluminiscencia (B) del sitio Los Nogales.

\begin{tabular}{|l|c|c|c|c|c|}
\hline \multicolumn{1}{|c|}{ Código laboratorio } & Material & Unidad & Nivel & Ańos AP & Fecha DC \\
\hline A. Radiocarbono (14C) & & & & & $\begin{array}{c}\text { Calibración 2 o } \\
\text { DC (95.4\%) }\end{array}$ \\
\hline UGAMS_8281 & Óseo humano & 4 & $\begin{array}{c}\text { Rasgo1 } \\
\text { Entierro }\end{array}$ & $1120 \pm 25$ & $783-990$ \\
\hline UGAMS_8284 & Carbón & 4 & $\begin{array}{c}\text { Rasgol } \\
\text { Entierro }\end{array}$ & $1110 \pm 30$ & $879-1013$ \\
\hline UGAMS_5982 & Carbón & 1 & - & $620 \pm 25$ & $1293-1399$ \\
\hline UGAMS_5976 & Óseo humano & 1 & - & $600 \pm 20$ & $1300-1406$ \\
\hline UGAMS_5979 & Óseo camélido & 1 & - & $430 \pm 25$ & $1426-1608$ \\
\hline UGAMS_8278 & Óseo camélido & 1, Ampliación & $\begin{array}{c}\text { Rasgo } \\
20-40 \mathrm{~cm}\end{array}$ & $340 \pm 30$ & $1470-1640$ \\
\hline
\end{tabular}

(OxCal v4.3.2 Bronk Ramsey (2017); r:5 IntCAl13 atmospheric curve (Reimer et al., 2013))

\begin{tabular}{|c|c|c|c|c|}
\hline \multicolumn{5}{|c|}{$\begin{array}{l}\text { B. Termoluminiscencia } \\
\text { (TL) }\end{array}$} \\
\hline UCTL2101 & $\begin{array}{c}\text { Borde rojo engobe } \\
\text { int/ext }\end{array}$ & 1 & $630 \pm 50$ & 1380 \\
\hline UCTL2102 & $\begin{array}{l}\text { Monocromo } \\
\text { alisado ext/int. }\end{array}$ & 1 & $645 \pm 65$ & 1365 \\
\hline UCTL2103 & $\begin{array}{c}\text { Aconcagua } \\
\text { salmón: monocromo } \\
\text { alisado ext, } \\
\text { blanco/salmón int. }\end{array}$ & 1 & $650 \pm 65$ & 1360 \\
\hline
\end{tabular}

Fuente: Pavlovic, 2010. 


\section{Materiales y métodos}

\section{Materiales}

En Los Nogales se identificaron fragmentos de cinco crisoles perforados y siete moldes. Morfológicamente, los crisoles son recipientes cóncavos de 39-64 mm de altura y 86-119 mm de diámetro (Figura 1A). Las paredes presentan una forma lenticular, esto es, más ancha en el centro (16-26 mm) y más delgada en los extremos $(5-13 \mathrm{~mm})$. Los cinco crisoles presentan un agujero circular en la base, el cual era más ancho en su parte superior $(14-19 \mathrm{~mm})$ y más cerrado en la parte inferior $(10-16 \mathrm{~mm})$. Las capacidades máximas se calcularon entre $80-104 \mathrm{~cm}^{3}$. La pasta de los crisoles es gris oscura, ${ }^{6}$ con mucha cantidad de arena y fragmentos de roca de gran tamaño. Los bordes tienen poros redondeados, evidencia de vitrificación. Todas las piezas estaban cubiertas por dentro y por fuera por una fina capa de pasta blanca.

Los moldes presentan una forma parecida a un ladrillo, con la superficie plana y la base ligeramente redondeada (Figura 1B). Sus dimensiones son de 39-43 mm de espesor y 78-94 mm de ancho; el largo no se pudo determinar por estar incompletos. Algunas superficies presentan bajorrelieves con diseńos rectangulares y redondeados. El color de la pasta varía de un rojo-café y un café oliva claro a un café grisáceo y gris. ${ }^{7}$ La pasta -muy suelta y quebradiza- contiene gran cantidad de arena y se observaron pequeñas inclusiones blancas. Una cobertura blanca cubría la superficie y los lados de los moldes, sin presentarse en la base o caras fracturadas internas, reforzando la idea de que esta pasta no es posdepositacional.

\section{Métodos de análisis}

De las 12 cerámicas metalúrgicas, se sometieron a análisis técnicos dos fragmentos de moldes y dos de crisoles. Todas las muestras fueron montadas como secciones transversales en bloques metalográficos de resina epoxy siguiendo procedimientos estándar, pulidas hasta un tamaño de grano de $1 \mu \mathrm{m}$ y examinadas usando un microscopio óptico Leica DM-LM. Los bloques fueron posteriormente cubiertos por una capa de carbono y se analizó su microestructura y composición química utilizando un microscopio electrónico de barrido (SEM en inglés) conectado a un espectrómetro de energía dispersa operado a $20 \mathrm{kV}$ (EDS en inglés). Los resultados se presentan en óxidos estequiométricos, reportados como porcentaje en peso. Dada la porosidad de las matrices cerámicas y fluctuaciones en la intensidad del haz de electrones, los totales analíticos son a menudo inferiores a $100 \%$, pero se presentan aquí normalizados para facilitar la comparación entre muestras.

Las pastas se caracterizaron también a partir de un análisis petrográfico. Se prepararon cuatro láminas delgadas siguiendo protocolos establecidos, y se examinaron utilizando un microscopio de luz polarizada Leica DM-EP. La identificación y registro de los atributos composicionales se realizaron siguiendo los parámetros propuestos por Quinn (2013, p. 80). Para determinar la mineralogía de la pasta y la cobertura blanca, se aplicó difracción de rayos-x (XRD en inglés) utilizando un difractrómetro XPERT-PRO con una radiación de CoKa $(\lambda=1,78901)$ a $40 \mathrm{kV}$ y $30 \mathrm{~mA}$. La naturaleza y origen de la cobertura exterior blanca se caracterizó también mediante espectroscopia de infrarrojos por transformadas de Fourier (FTIR en inglés), utilizando un espectrómetro Perkin Elmer 2000 con 30 barridos a una precisión de $4 \mathrm{~cm}^{-1}$ (detalles en Plaza y Martinón-Torres, 2015).

6 Código 10Y 4/1 en la Carta de color Munsell.

7 Código 5YR 5/4; 2,5Y 5/3; 2,5Y 5/2 y 2,5Y 6/1 en la Carta de color Munsell. 
Los análisis se realizaron en el Wolfson Archaeological Science Laboratory del Instituto de Arqueología y el X-Ray Diffraction Laboratory del Departamento de Ciencias de la Tierra, ambos en la University College London.

\section{Resultados}

\section{Manufactura y materias primas}

La petrografía indica que moldes y crisoles fueron hechos de pastas similares. Ambos grupos cerámicos (moldes y crisoles) presentan gran cantidad de inclusiones $(50-45 \%)$ y poros (15$20 \%)$, y un bajo porcentaje de arcilla (35\%). La pasta de los moldes es de grano grueso, compuesta por inclusiones de rocas volcánicas y plutónicas de tamańo grueso a mediano $(<2 \mathrm{~mm}$, moda $=0,6 \mathrm{~mm}$ ) y abundantes inclusiones de hueso en una matriz arcillosa no calcárea color café-rojiza. Los fragmentos de rocas ígneas y el hueso molido presentaron tamańos uniformes sugiriendo que fueron agregados como antiplástico. La pasta de los crisoles comparte las mismas características, excepto que no contiene hueso molido como antiplástico (Figura 4).

Tabla 3. Lista de las inclusiones identificadas por petrografía en moldes y crisoles.

\begin{tabular}{|c|c|c|}
\hline \multicolumn{3}{|c|}{ Inclusiones presentes en moldes y crisoles $\left(50-45 \%\right.$ vol $\left.^{*}\right)$. } \\
\hline & Moldes (R1/R2) & Crisoles (R3/R4) \\
\hline Frag. de hueso & Frecuente & Ausente \\
\hline Frag. rocas intermedias & Comunes & Frecuentes \\
\hline Frag. rocas volcánicas básicas & Pocas & Comunes \\
\hline Cuarzo microcristalino/feldespatos & Pocas & Comunes \\
\hline Plagioclasa & Pocas & Comunes \\
\hline Hornblenda & Muy pocas & Ausente \\
\hline Incl. ferrosas & Muy pocas & Muy pocas \\
\hline Cuarzo & Muy raras & Raras \\
\hline Piroxeno & Muy raras & Muy raras \\
\hline Muscovita & Muy raras & Ausente \\
\hline Ortoclasa & Muy raras & Ausente \\
\hline Frag. rocas sedimentarias & Muy raras & Ausente \\
\hline Epidota & Muy raras & Ausente \\
\hline Minerales alterados & Muy raras & Muy raras \\
\hline
\end{tabular}

Nota: Las inclusiones presentes en ambos grupos se destacan en negro. Frecuente $30-50 \%$; comunes $15-30 \%$; pocas $5-15 \%$; muy pocas $2-5 \%$; raras $0,5-2 \%$; muy raras $<0,5 \%$. Vol: volumen. 


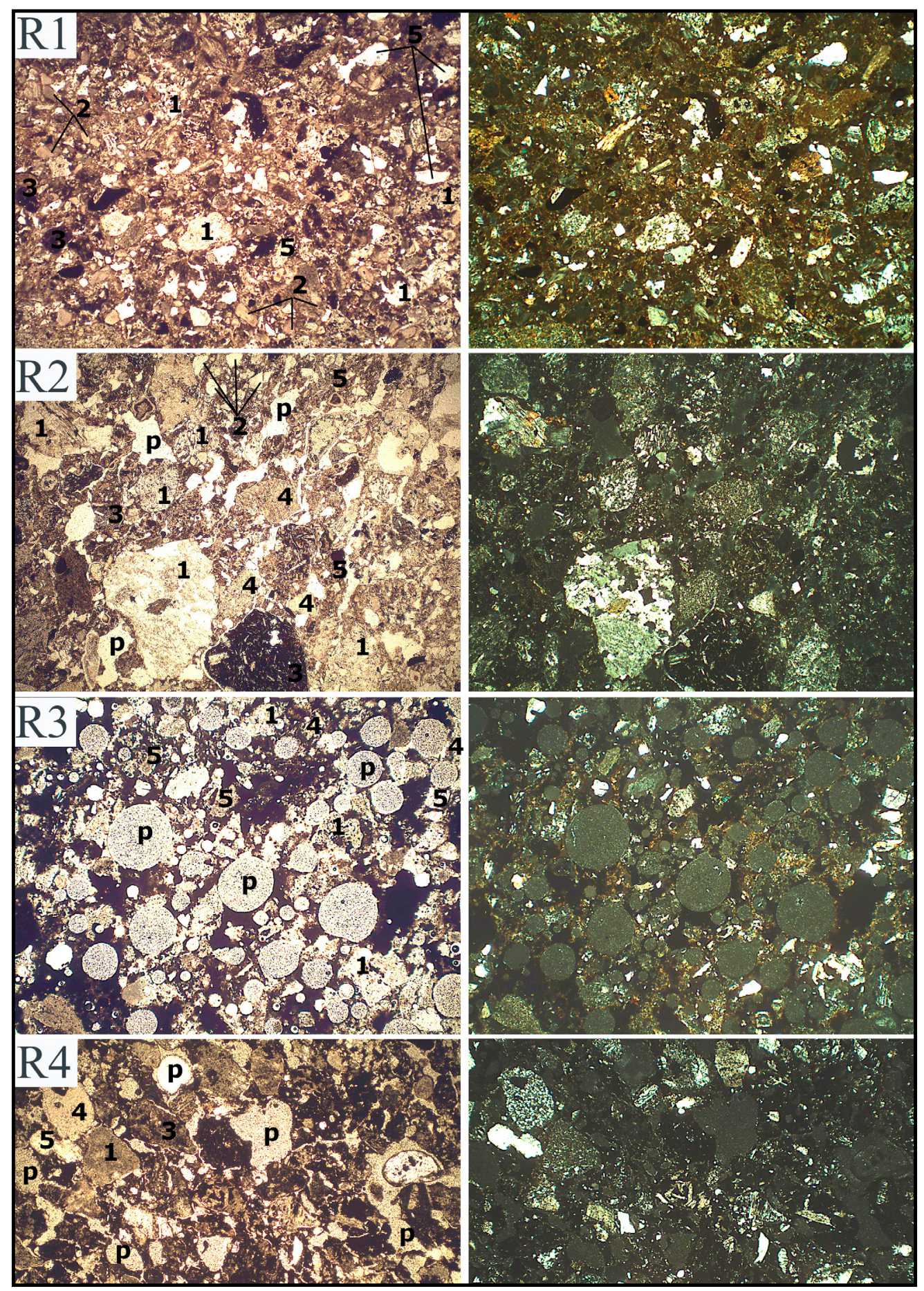

Figura 4. Imágenes de las secciones delgadas utilizando un microscopio de luz polarizada transmitida en campo claro (izquierda) y campo oscuro (derecha). R1/R2: moldes; R3/R4: crisoles. Se indican las principales inclusiones y fragmentos de roca: 1. Rocas intermedias; 2. Inclusiones de hueso; 3. Rocas ígneas básicas; 4. Cuarzo y feldespatos microcristalinos; 5. Feldespatos de plagioclasas; p- Poros. Imágenes: $6 \mathrm{~mm}$ ancho. 
La mayor parte de las inclusiones $(65-98 \%$ vol) corresponden a rocas ígneas intermedias y sus minerales asociados como plagioclasas, hornablenda y minerales ferrosos (Tabla 3). También se identificó cuarzo, piroxenas, mica, feldespatos (ortoclasas), epidota y algunos fragmentos de roca sedimentaria y minerales alterados. Potenciales rocas parentales son microdiorita, andesita y basaltos. El tamaño de estas inclusiones se define como medio a muy grueso $(<2 \mathrm{~mm}$, moda $=0,6 \mathrm{~mm}$ ) con una ordenación equilibrada (Orton, Tyers y Vince, 1997). El desgaste o forma de las inclusiones es principalmente subangular y redondeado. La variedad de rocas ígneas, ordenación de los tamaños y su desgaste sugieren que estos antiplásticos derivan de depósitos aluviales. La presencia de algunos minerales individuales sin desgaste -generalmente asociados a depósitos primarios- indicaría el uso de una arcilla residual que fue transportada a cortas distancias. El mapa geológico del área de Los Nogales (área de Los Andes) muestra que este tipo de inclusiones se encuentran localmente: sedimentos aluviales formados por la meteorización de basaltos, andesitas, dacitas y granodioritas que serían característicos del área (Figura 5) (Sernageomin, 2003).

En los moldes, el hueso empleado como antiplástico representa un $30-50 \%$ de las inclusiones. $\mathrm{La}$ angulosidad de los fragmentos de hueso indica que estos fueron machacados. Su buena ordenación y su rango de tamaño fino $(<0,6 \mathrm{~mm}$, moda $=0,3 \mathrm{~mm})$ indica que probablemente fueron colados antes de ser utilizados. El XRD detectó hidroxiapatita (HAp), componente principal de los huesos, confirmando su uso como antiplástico en moldes y su ausencia en los crisoles (Anexo 1).

Los poros representan un 15-25\% vol. En moldes la mayoría corresponde a meso y macro poros de forma irregular. En crisoles la porosidad es mayor y se observan poros redondeados -en especial en el crisol R3- indicando distintos niveles de vitrificación. No se detectó ninguna alineación u ordenamiento. La matriz arcillosa es escasa, representando un 35\% vol.

La composición química general de las pastas cerámicas obtenidas por SEM-EDS coincide con la petrografía (Tabla 4). Los resultados muestran que el componente principal es sílice (38,9-59,2\%), seguido en los crisoles por alúmina (18,6-19,1\%) y en los moldes por óxido de calcio (22-13,8\%), óxido de fósforo (17,6-10,0\%) y alúmina (11,7-14,9\%). El porcentaje de óxido de hierro es 10,2-4,0\%, mientras que bajo un 5\% se identificaron óxidos de sodio, magnesio, titanio y manganeso. El alto porcentaje de óxido de calcio y fósforo en moldes se debe al uso de hueso molido como antiplástico. Los altos niveles de óxido de sodio se explican por la composición de las inclusiones volcánicas intermedias y básicas usadas también como antiplástico, las cuales están formadas por abundantes feldespatos ricos en sodio, como son los minerales de albita, oligoclasa, andesina y anortita detectados por XRD. Este análisis también detectó enstatita, diópsido y espinela, los cuales explican el alto porcentaje de óxido de magnesio.

El tipo de arcilla utilizada se determinó a partir de XRD. En los moldes se identificó montmorillonita, mientras que en los crisoles no se encontraron minerales de arcilla pero se detectó espinela, que pudiera corresponder a una transformación de la montmorillonita a altas temperaturas (Rice, 2005, p. 92), sugiriendo su uso como arcilla. La montmorillonita pertenece a la familia de la esmectita, formada por la alteración de rocas básicas o ceniza volcánica. Esta es muy plástica, pero su resistencia a altas temperaturas es limitada (Rice, 2005). El resultado de los análisis de composición química realizados en la matriz arcillosa (evitando poros e inclusiones) se presenta en la Tabla 5A. A pesar de que se evitaron las inclusiones más grandes durante el análisis, la notable presencia de óxido de calcio $(\mathrm{CaO})$ y óxido de fósforo 
Tabla 4. Composición química general de las pastas cerámicas de moldes y crisoles por SEM-EDS.

\begin{tabular}{|c|c|c|c|c|c|c|c|c|c|c|c|}
\hline \multicolumn{10}{|c|}{ Composición química general de las pastas cerámicas, wt\% } \\
\hline & $\mathbf{N a}_{2} \mathbf{O}$ & $\mathbf{M g O}$ & $\mathbf{A l}_{2} \mathbf{O}_{3}$ & $\mathbf{S i O}_{2}$ & $\mathbf{P}_{2} \mathbf{O}_{5}$ & $\mathbf{C l}$ & $\mathbf{K}_{2} \mathbf{O}$ & $\mathbf{C a O}$ & $\mathbf{T i O}_{2}$ & $\mathbf{M n O}$ & $\mathbf{F e O}$ \\
\hline $\begin{array}{c}\mathrm{R} 1- \\
\text { Molde }\end{array}$ & 2,7 & 1,2 & 11,7 & 38,9 & 17,6 & 0,2 & 1,2 & 22,0 & 0,6 & nd & 4,0 \\
\hline $\begin{array}{c}\text { R2 }- \\
\text { Molde }\end{array}$ & 3,4 & 1,6 & 14,9 & 49,1 & 10,0 & 0,2 & 1,3 & 13,8 & 0,6 & nd & 5,1 \\
\hline $\begin{array}{c}\text { R3 - } \\
\text { Crisol }\end{array}$ & 3,3 & 2,1 & 18,6 & 57,6 & nd & nd & 1,8 & 4,9 & 1,4 & 0,1 & 10,2 \\
\hline $\begin{array}{c}\text { R4 }- \\
\text { Crisol }\end{array}$ & 4,2 & 2,1 & 19,1 & 59,2 & nd & 0,1 & 2,0 & 4,6 & 1,0 & nd & 7,8 \\
\hline
\end{tabular}

Resultados son el promedio de cinco medidas en áreas de 1200x1000 $\mu \mathrm{m}$ evitando grandes poros. Los resultados están normalizados al $100 \%$. nd: no detectado (modificado de Plaza y Martinón-Torres, 2015, tabla 4).

$\left(\mathrm{P}_{2} \mathrm{O}_{5}\right)$ en los moldes probablemente corresponde al fosfato de calcio que compone la Hap, $\mathrm{Ca}_{5}\left(\mathrm{PO}_{4}\right)_{3}(\mathrm{OH})$ (Rivera-Muñoz, 2011).

Para comparar químicamente las matrices de los moldes y crisoles con independencia de las inclusiones, se extrajo la composición de la HAp de los primeros utilizando un método semicuantitativo aplicado anteriormente en el estudio de las copelas (protocolo completo en Martinón-Torres, Rehren, Thomas y Mongiatti, 2009). Mediante este método se calcula el porcentaje de fosfato de calcio presente en la matriz de los moldes y se extrae del total. Esta cifra es renormalizada al 100\%, permitiendo obtener la composición de la matriz original de los moldes sin HAp. Los datos renormalizados (Tabla 5C) indican que la arcilla utilizada en la manufactura de las cerámicas está compuesta principalmente por sílice (54-60\%), alúmina (17-23\%), óxido de hierro (6-12\%) y baja cantidad de óxidos de calcio, sodio, magnesio, titanio, potasio y manganeso $(<5 \%)$. Al graficar estas composiciones en un diagrama ternario basado en la composición química de los minerales de arcilla (Tite, Freestone, Meeks y Bimson, 1982, p. 112), los resultados caen dentro del área de la familia de las illitas y esmectitas, corroborando la información del XRD que identificó dos minerales de esta familia: espinela y montmorillonita (Figura 6). 
Tabla 5. Composición química de la matriz arcillosa de las cerámicas técnicas por SEM-EDS.

A) Composición química de la matriz arcillosa de moldes y crisoles, wt\%

\begin{tabular}{|c|c|c|c|c|r|r|r|r|r|r|c|}
\hline & $\mathbf{N a}_{2} \mathbf{O}$ & $\mathbf{M g O}$ & $\mathbf{A l}_{2} \mathbf{O}_{\mathbf{3}}$ & $\mathbf{S i O}_{2}$ & $\mathbf{P}_{2} \mathbf{O}_{5}$ & $\mathbf{C l}$ & $\mathbf{K}_{2} \mathbf{O}$ & $\mathbf{C a O}$ & $\mathbf{T i O}_{2}$ & $\mathbf{M n O}$ & $\mathbf{F e O}$ \\
\hline $\begin{array}{c}\mathrm{R} 1- \\
\text { Molde }\end{array}$ & 0,6 & 3,1 & 19,4 & 49,1 & 8,1 & 0,1 & 0,9 & 10,7 & 0,5 & nd & 7,4 \\
\hline $\begin{array}{c}\mathrm{R} 2- \\
\text { Molde }\end{array}$ & 1,6 & 2,6 & 18,7 & 41,2 & 10,5 & 0,3 & 1,5 & 16,8 & 0,7 & nd & 6,1 \\
\hline $\begin{array}{c}\text { R3 - } \\
\text { Crisol }\end{array}$ & 3,4 & 1,9 & 17,6 & 58,0 & 0,2 & nd & 1,6 & 3,8 & 1,4 & 0,1 & 11,9 \\
\hline $\begin{array}{c}\text { R4 - } \\
\text { Crisol }\end{array}$ & 3,9 & 1,6 & 23,7 & 57,1 & nd & nd & 2,2 & 4,3 & 0,5 & nd & 6,8 \\
\hline
\end{tabular}

B) Composición química de las inclusiones de hueso en la pasta cerámica, wt $\%$

\begin{tabular}{|c|c|c|c|c|c|c|c|c|c|c|c|}
\hline $\begin{array}{c}\text { R1 - } \\
\text { Molde }\end{array}$ & nd & 0,6 & 0,6 & 0,5 & 41,7 & 1,3 & nd & 54,9 & nd & nd & 0,4 \\
\hline
\end{tabular}

ratio $\mathrm{CaO} / \mathrm{P} 2 \mathrm{O} 5: \mathbf{1 , 3}$

C) Resultados re-normalizados, substrayendo el $\mathrm{CaO}$ y $\mathrm{P}_{2} \mathrm{O}_{5}$ de la matriz arcillosa, wt $\%$

\begin{tabular}{|c|c|c|c|c|c|c|c|c|c|c|c|}
\hline & $\mathbf{N a}_{\mathbf{2}} \mathbf{O}$ & $\mathbf{M g O}$ & $\mathbf{A l}_{\mathbf{2}} \mathbf{O}_{\mathbf{3}}$ & $\mathbf{S i O}_{\mathbf{2}}$ & $\mathbf{P}_{\mathbf{2}} \mathbf{O}_{\mathbf{5}}$ & $\mathbf{C l}$ & $\mathbf{K}_{\mathbf{2}} \mathbf{O}$ & $\mathbf{C a O}$ & $\mathbf{T i O}_{2}$ & $\mathbf{M n O}$ & $\mathbf{F e O}$ \\
\hline $\begin{array}{c}\mathrm{R} 1- \\
\text { Molde }\end{array}$ & 0,8 & 3,9 & 23,8 & 60,3 & - & 0,2 & 1,2 & 0,2 & 0,6 & $\mathrm{nd}$ & 9,1 \\
\hline $\begin{array}{c}\mathrm{R} 2- \\
\text { Molde }\end{array}$ & 2,1 & 3,4 & 24,6 & 54,4 & - & 0,4 & 2,0 & 4,1 & 1,0 & $\mathrm{nd}$ & 8,0 \\
\hline $\begin{array}{c}\text { R3 }- \\
\text { Crisol }\end{array}$ & 3,4 & 1,9 & 17,7 & 58,2 & - & $\mathrm{nd}$ & 1,6 & 3,6 & 1,4 & 0,1 & 12,0 \\
\hline $\begin{array}{c}\text { R4 }- \\
\text { Crisol }\end{array}$ & 3,9 & 1,6 & 23,7 & 57,1 & $\mathrm{nd}$ & $\mathrm{nd}$ & 2,2 & 4,3 & 0,5 & $\mathrm{nd}$ & 6,8 \\
\hline
\end{tabular}

Nota: A) Análisis puntuales de la matriz evitando poros e inclusiones, B) Análisis puntual en las inclusiones de hueso de la pasta cerámica, pieza R1. El alúmina, sílice y óxido de hierro se consideran contaminación de la matriz, C) Mismas cifras de A renormalizadas después de substraer el fosfato de calcio perteneciente al hueso (modificado de Plaza y Martinón-Torres, 2015). 


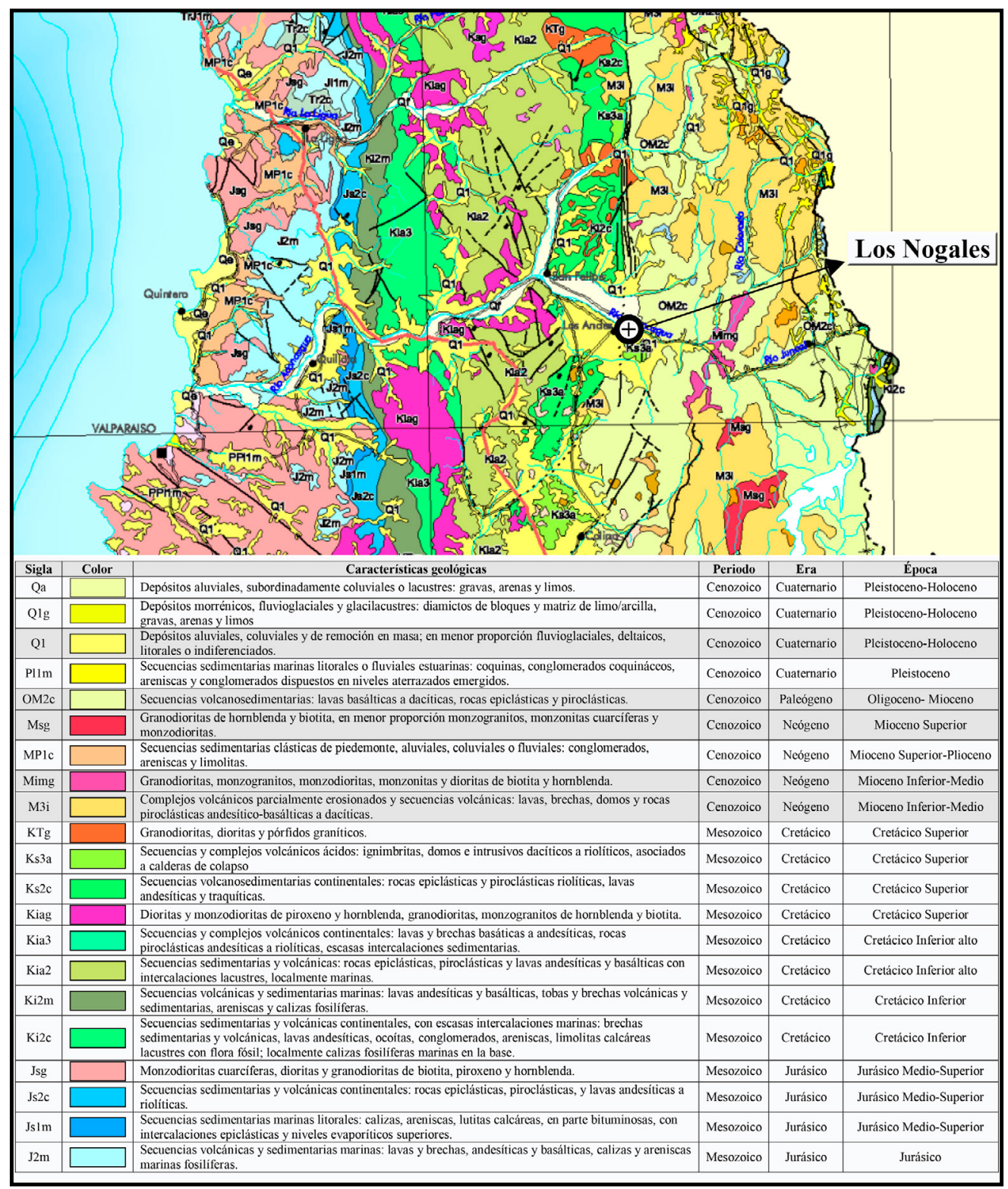

Figura 5. Mapa geológico del valle del Aconcagua escala 1:1.000.000, señalando el sitio Los Nogales. Se destacan en gris las posibles fuentes locales de las inclusiones de la pasta cerámica. Nótese sin embargo, que una gran variedad de rocas ígneas volcánicas y plutónicas están disponibles regionalmente. Referirse a la versión digital para ver los colores (modificado de Sernageomin, 2003). 


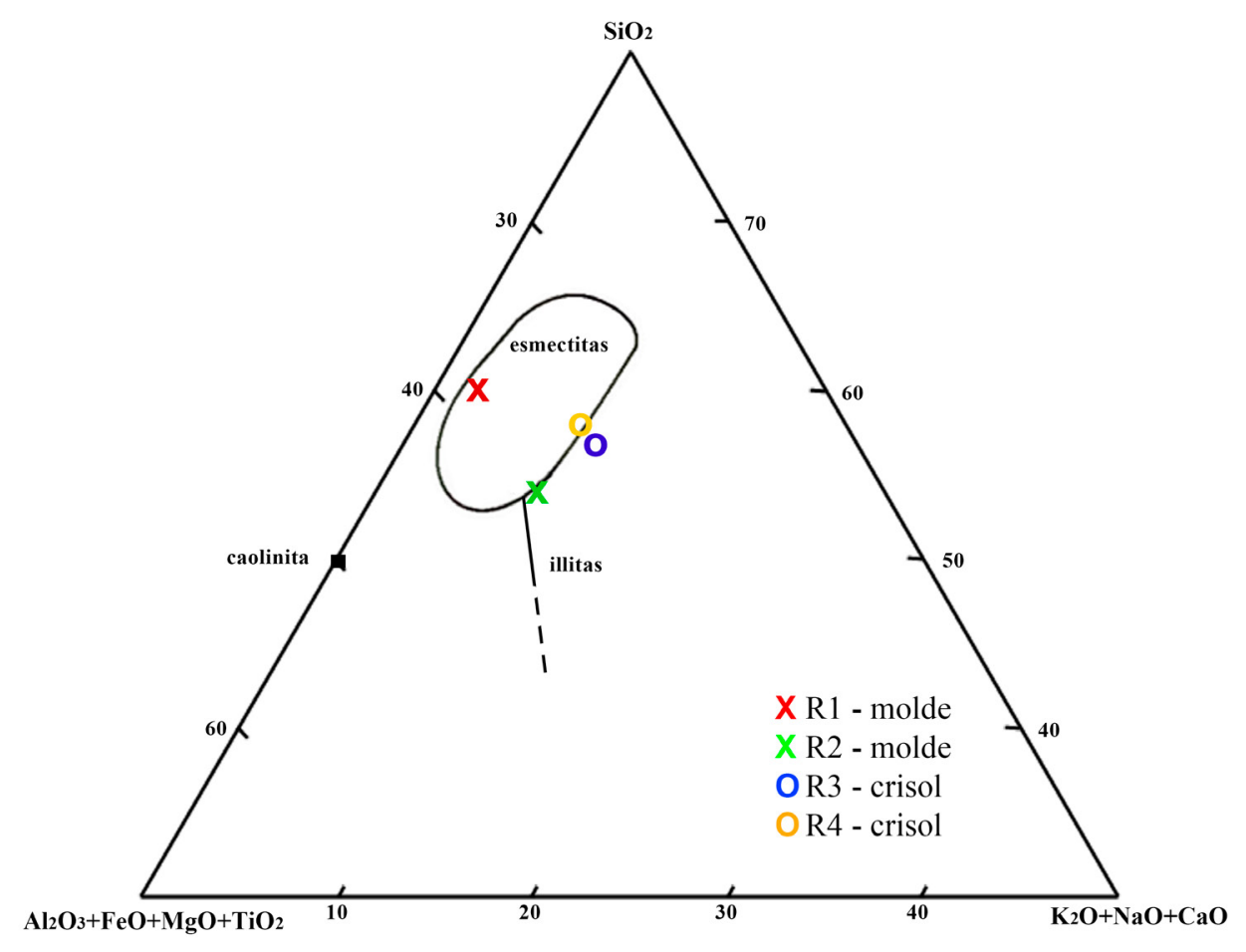

Figura 6. Diagrama ternario identificando el tipo de arcilla usada en moldes y crisoles de Los Nogales (Plaza y Martinón-Torres, 2015, fig. 5).

\section{Temperaturas de cocción}

Las estimaciones de las temperaturas de cocción fueron determinadas combinando los resultados de la petrografía, XRD y SEM, lo cual permitió establecer rangos más específicos.

En petrografía todas las piezas registraron matrices ópticamente inactivas, sugiriendo temperaturas sobre $800-850{ }^{\circ} \mathrm{C}$. En moldes, esto coincide con la presencia de minerales de hornablenda alterados, los cuales en condiciones oxidantes y sobre $750{ }^{\circ} \mathrm{C}$ cambian su color de verde a café (Quinn, 2013, p. 191). En los crisoles se observaron minerales fundidos y una mayor porosidad, indicando la aplicación de mayor temperatura, lo que produjo una matriz vítrea color negro. El crisol R3 presentó el mayor grado de vitrificación con poros redondeados producidos por la formación de vacuolas y distribuidos uniformemente por toda la matriz (Figura 4R3). La presencia de cuarzos fracturados y feldespatos fundidos sugiere el uso de temperaturas entre los 1100-1200 ${ }^{\circ} \mathrm{C}$ (Hammer y Hammer, 1993; Ohya y Takahashi, 1999; Quinn, 2013). En el crisol R4 se detectaron minerales alterados pero no fundidos, sugiriendo temperaturas por debajo de $1100{ }^{\circ} \mathrm{C}$.

Los rangos térmicos de los minerales detectados por XRD para moldes y crisoles están resumidos en la Figura 7. En los moldes, la presencia de montmorillonita, mineral que se descompone entre los $800-900{ }^{\circ} \mathrm{C}$ (Rice, 2005, p. 92), indica que estos no excedieron los $900{ }^{\circ} \mathrm{C}$. Por 
otro lado, la enstatita y gehlenita se forman entre los $800-900{ }^{\circ} \mathrm{C}$ (Grim y Kulbicki, 1961; Nodari, Marcuz, Maritan, Mazzoli y Russo, 2007), la magnetita y diópsido cristalizan a los $820-900{ }^{\circ} \mathrm{C}$ (Maritan, Mazzoli, Nodari y Russo, 2005, p. 41) y la anortita comienza su formación a los $800-850^{\circ} \mathrm{C}$ (Rasmussen, De La Fuente, Bond, Mathiesen y Vera, 2012, p. 1710; Yanik, Bozer, Çeken, Esenli y Gocmez, 2012, p. 266). Esto sugiere un rango de temperatura entre los 800-900 ${ }^{\circ} \mathrm{C}$ para la cocción de los moldes. En ambos crisoles se detectó espinela, la cual se forma alrededor de los $900{ }^{\circ} \mathrm{C}$ (Rice, 2005, p. 95); mientras que la presencia de gehlenita, enstatita, magnetita, diópsido y anortita indica claramente temperaturas sobre los 800 ${ }^{\circ} \mathrm{C}$. La cristobalita se forma a los $1050{ }^{\circ} \mathrm{C}$ (Rice, 2005, p. 95); sin embargo esta temperatura puede disminuir a $900-950^{\circ} \mathrm{C}$ en una matriz rica en óxido de sodio (Na2O; Cole, 1935, pp.

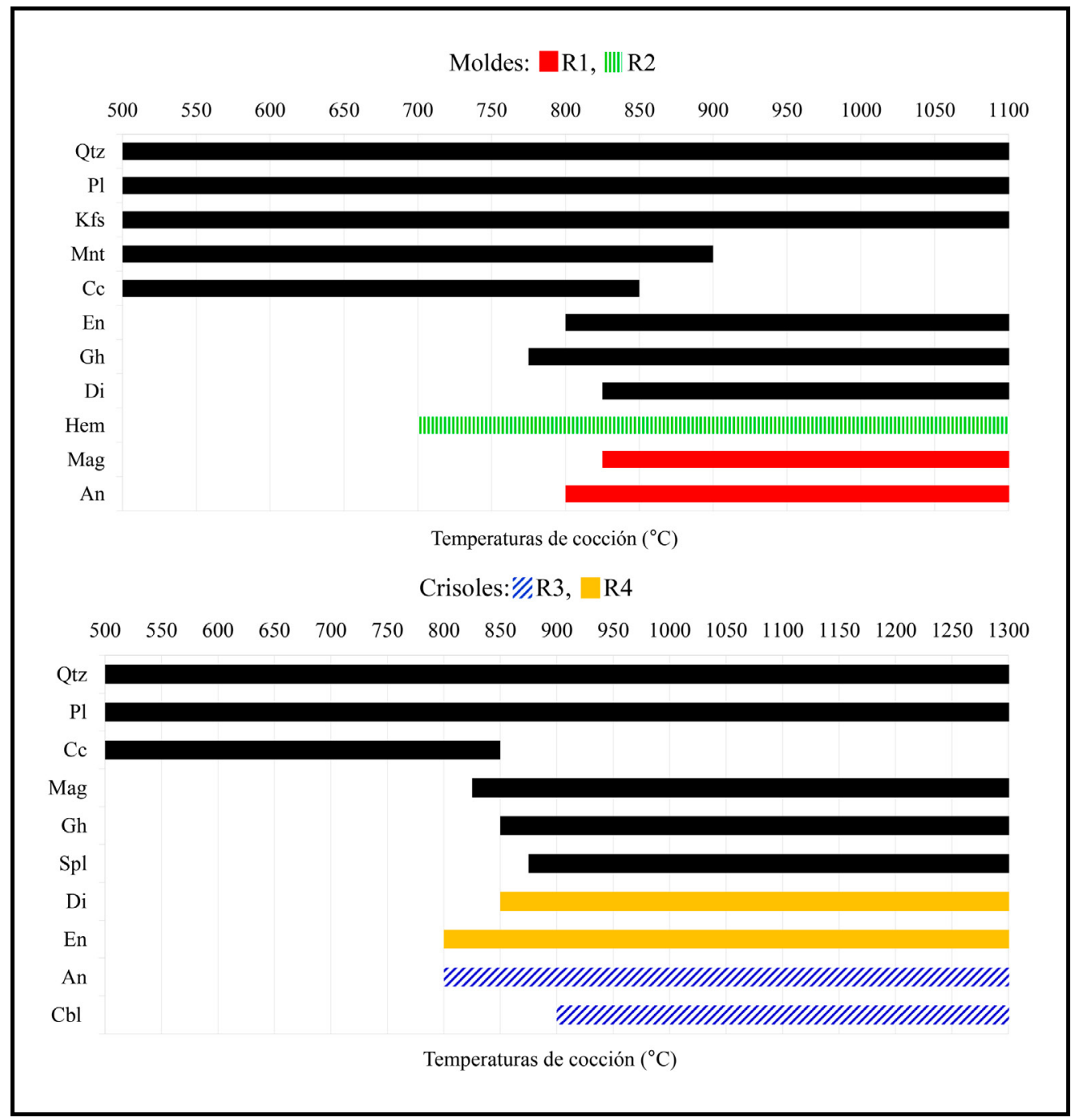

Figura 7. Comportamiento térmico de algunos de los minerales identificados por XRD en moldes y crisoles. Las barras negras indican minerales encontrados en ambas muestras analizadas. Las barras de colores, minerales identificados solo en una de las muestras. Minerales: Qtz: cuarzo, Pl: plagioclasas (albita y andesina), Kfs: feldespatos de potasio, Mnt: monsmorillonita, Cc: calcita, En: enstatita, Gh: gehlenita, Di: diópsido, Hem: hematita, Mag: magnetita, An: anortita, Spl: espinela, Cbl: cristobalita (modificado de Plaza y Martinón-Torres, 2015, fig. 6). 
151-153), condiciones presentes en las muestras analizadas que contienen hasta $4 \%$ de $\mathrm{Na}_{2} \mathrm{O}$ como muestra la composición química general de las pastas (ver Tabla 5). Estas temperaturas sugieren un rango que supera los $900^{\circ}$ y posiblemente bajo los $1050{ }^{\circ} \mathrm{C}$ para los crisoles.

La última estimación se hizo sobre la base del grado de vitrificación observado en cortes frescos de las pastas bajo el SEM (Maniatis y Tite, 1981; Wolf, 2002; Hein, Kilikoglou y Kassianidou, 2007; Hein, Müller, Day y Kilikoglou, 2008). Se ha propuesto una correlación entre los grados de vitrificación, composición química, atmósferas y temperaturas de cocción para arcillas no calcáreas (Maniatis y Tite, 1981; Wolf, 2002). Sin embargo, estas correlaciones deben ser tomadas como estimaciones, ya que comparaciones exactas son imposibles por varias razones. Primero, la generación de fases vítreas está estrechamente relacionada a la composición de las arcillas, por lo tanto pastas distintas reaccionan de manera diferente. Segundo, los experimentos que determinan las características de estas fases se basan en el recocido de fragmentos cerámicos bajo condiciones controladas, que no corresponden necesariamente a las condiciones usadas en la antigüedad (Maniatis y Tite, 1981; Wolf, 2002). A pesar de lo anterior, estas estimaciones son útiles para generar una idea de los rangos térmicos utilizados.

Según Maniatis y Tite (1981) las atmósferas de cocción afectan activamente la vitrificación de una pasta. En condiciones reductoras la vitrificación comienza a temperaturas más bajas, alrededor de $50{ }^{\circ} \mathrm{C}$ menos que en condiciones oxidantes. En el caso de las cerámicas analizadas, los moldes presentaron pastas color rojizo con áreas grises; mientras que el XRD indicó la presencia de hematita y magnetita. En general pastas rojizas y la presencia de hematita indican condiciones oxidantes, mientras que pastas grises y la magnetita sugieren condiciones reductoras. Esta variabilidad muestra que los moldes fueron cocidos en condiciones inestables, con flujos de oxígeno variables. Por el contrario, los crisoles presentaron pastas negras, con minerales de magnetita y hercinita, los cuales se forman bajo condiciones moderadas a fuertemente reductoras (Maggetti, 1982, p. 129; Maritan et al., 2005, p. 41). Dado lo anterior, para establecer el grado de vitrificación se consideró que los moldes fueron sometidos a condiciones oxidantes, mientras que los crisoles a condiciones reductoras.

En la Tabla 6 se resumen las características de los diferentes estados de vitrificación, y en la Figura 8 se presentan las características de las cerámicas técnicas analizadas. Se identificaron tres estadios de vitrificación en las piezas de Los Nogales: ambos moldes presentan una vitrificación inicial, caracterizada por la fusión parcial de los granos y la aparición de filamentos vítreos aislados, pero manteniendo una textura en capas. Se estima la aplicación de temperaturas entre $800-850{ }^{\circ} \mathrm{C}$. El crisol R4 presentó una textura entre vitrificación inicial avanzada y vitrificación extensa, estimándose una cocción a temperaturas entre $800-950{ }^{\circ} \mathrm{C}$. El crisol R3 es el más vitrificado, presentando un estado de vitrificación continua con grandes poros redondeados $(>500 \mu \mathrm{m})$ producidos por escape de gases, y se estima el uso de temperaturas entre $1000-1100{ }^{\circ} \mathrm{C}$. 
Tabla 6. Características y rangos de temperatura de los diferentes estadios de vitrificación en arcillas no-calcáreas.

\begin{tabular}{|c|c|c|c|}
\hline \multicolumn{4}{|c|}{ Fases de vitrificación en arcillas no-calcáreas } \\
\hline \multirow{2}{*}{$\begin{array}{l}\text { Grado de } \\
\text { vitrificación }\end{array}$} & \multirow{2}{*}{ Descripción } & \multicolumn{2}{|c|}{$\begin{array}{c}\text { Atmósferas y temperaturas } \\
\text { estimadas }\end{array}$} \\
\hline & & Oxidante & Reductora $^{1}$ \\
\hline $\begin{array}{l}\text { Sin vitrificación } \\
(\mathrm{NV})\end{array}$ & $\begin{array}{c}\text { - Minerales de arcilla presentan una textura } \\
\text { laminar }\end{array}$ & $<800^{\circ} \mathrm{C}$ & $<750^{\circ} \mathrm{C}$ \\
\hline $\begin{array}{l}\text { Vitrificación } \\
\text { temprana }(\mathrm{NV}+)\end{array}$ & $\begin{array}{l}\text { - No hay superficies lisas (vítreas) definidas } \\
\text { - Los bordes de los minerales de arcilla } \\
\text { se redondean } \\
\text { - Las primeras evidencias de vitrificación } \\
\text { ocurren alrededor de los } 800^{\circ} \mathrm{C}\end{array}$ & $-800^{\circ} \mathrm{C}$ & $-750^{\circ} \mathrm{C}$ \\
\hline $\begin{array}{l}\text { Vitrificación } \\
\text { inicial (IV) }\end{array}$ & $\begin{array}{l}\text { - Aparición de áreas lisas como filamentos } \\
\text { vítreos aislados } \\
\text { - Fusión parcial de los bordes de los granos } \\
\text { de minerales de arcilla. }\end{array}$ & $800-850^{\circ} \mathrm{C}$ & $750-800^{\circ} \mathrm{C}$ \\
\hline IV avanzada (IV+) & $\begin{array}{l}\text { - Se amalgaman y fusionan fuertemente } \\
\text { los minerales de arcilla } \\
\text { - Se pierde la textura laminar de los granos }\end{array}$ & $850-900^{\circ} \mathrm{C}$ & $800-850^{\circ} \mathrm{C}$ \\
\hline $\begin{array}{l}\text { Vitrificación } \\
\text { extensiva }(V)\end{array}$ & $\begin{array}{l}\text { - Incremento constante de las áreas vítreas aisladas } \\
\text { • Microestructura esponjosa a la vista }\end{array}$ & $900-1000^{\circ} \mathrm{C}$ & $850-950^{\circ} \mathrm{C}$ \\
\hline $\begin{array}{l}\text { Vitrificación } \\
\text { continua }(\mathrm{CV})\end{array}$ & $\begin{array}{l}\text { - Las áreas vítreas se funden para formar una capa } \\
\text { vitrificada continua, visible por toda la superficie } \\
\qquad \text { de fractura } \\
\text { - Las áreas vítreas aisladas se funden entre ellas }\end{array}$ & $1000-1100^{\circ} \mathrm{C}$ & $950-1050^{\circ} \mathrm{C}$ \\
\hline $\begin{array}{l}\text { Estadio de } \\
\text { vitrificación final } \\
(\mathrm{CV}[\mathrm{CB} 2])\end{array}$ & $\begin{array}{l}\text { - Los poros redondeados incrementan su tamaño } \\
\qquad(10-50 \mathrm{~mm}) \\
\text { - Se forman grandes poros desconectados entre sí, } \\
\text { dentro de una matriz vítrea continua. }\end{array}$ & $1100-1150^{\circ} \mathrm{C}$ & $1000-1100^{\circ} \mathrm{C}$ \\
\hline
\end{tabular}

Nota: Tomado y modificado de Maniatis y Tite (1981) y Wolf (2002). 1. Se estima que la vitrificación comienza a unos $50{ }^{\circ} \mathrm{C}$ menos en una atmósfera reductora. 2. CB: grandes poros redondeados producidos por escape de gases. 


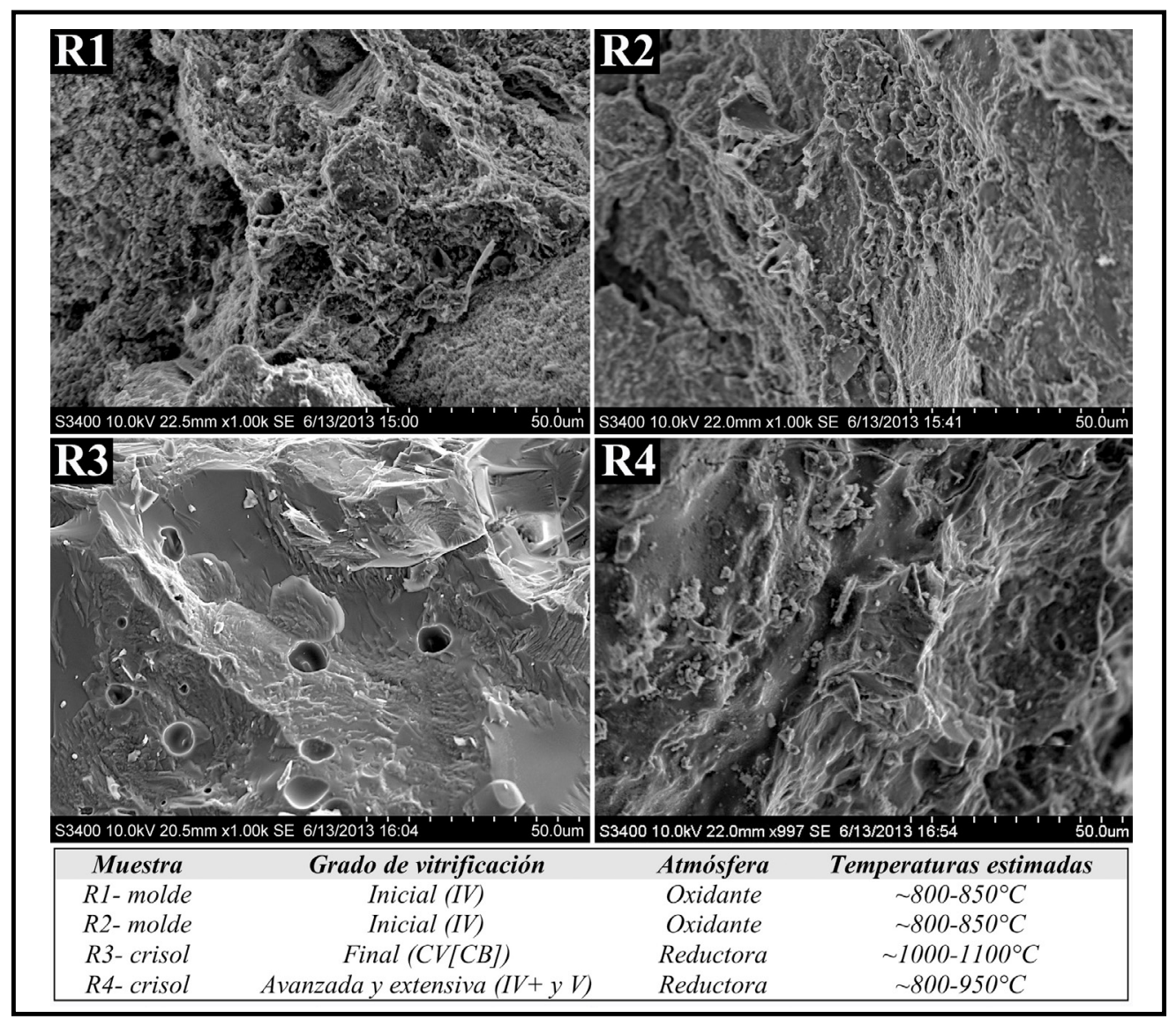

Figura 8. Imágenes de electrón secundario de cortes frescos de los cuerpos de las cerámicas por SEM y sus estados de vitrificación. Nótense las diferentes texturas entre los moldes R1/R2 y crisoles R3/R4; los últimos se encuentran más vitrificados. Los grados de vitrificación se definen en la Tabla 6. Imágenes: 127 mm de ancho (magnificación: 1000x).

Las temperaturas obtenidas por los distintos métodos descritos arriba se resumen en la Figura 9. Con base en el solapamiento de los resultados, se propone que las temperaturas de cocción más probables para los moldes van entre los $800-850^{\circ} \mathrm{C}$, mientras que para el crisol R4, entre $900-950{ }^{\circ} \mathrm{C}$. Sin embargo, las temperaturas propuestas para el crisol R3 no coinciden en tres de los métodos aplicados: mientras que en el XRD y SEM los resultados sugieren entre 1000$1050{ }^{\circ} \mathrm{C}$, el estudio petrográfico basado en la alteración térmica de los feldespatos y cuarzos indica $1100-1200^{\circ} \mathrm{C}$. Una posible explicación para esta discrepancia puede ser el efecto producido por la cocción en una atmósfera reductora, que según Maniatis y Tite (1981, p. 61) puede inducir a una vitrificación temprana, disminuyendo en $-50{ }^{\circ} \mathrm{C}$ las temperaturas esperadas. Por otra parte, Rice (2005, p. 97) plantea que la presencia de diferentes tipos de feldespatos puede reducir la temperatura de fusión. Dado lo anterior, es posible disminuir las temperaturas del crisol R3 de $1100 \mathrm{a} \sim 1050{ }^{\circ} \mathrm{C}$, acercándose a los resultados obtenidos por XRD y SEM. No obstante, hay que considerar que todos estos métodos son esencialmente cualitativos y que las condiciones de cocción en la prehistoria eran altamente variables (Gosselain, 1992). Así, en el caso de los crisoles, más que temperaturas exactas, lo que queda claro es que fueron sometidos a temperaturas mayores que los moldes, entre los cuales la pieza $\mathrm{R} 3$ habría alcanzado los rangos más altos, posiblemente alrededor de $1050{ }^{\circ} \mathrm{C}$. 


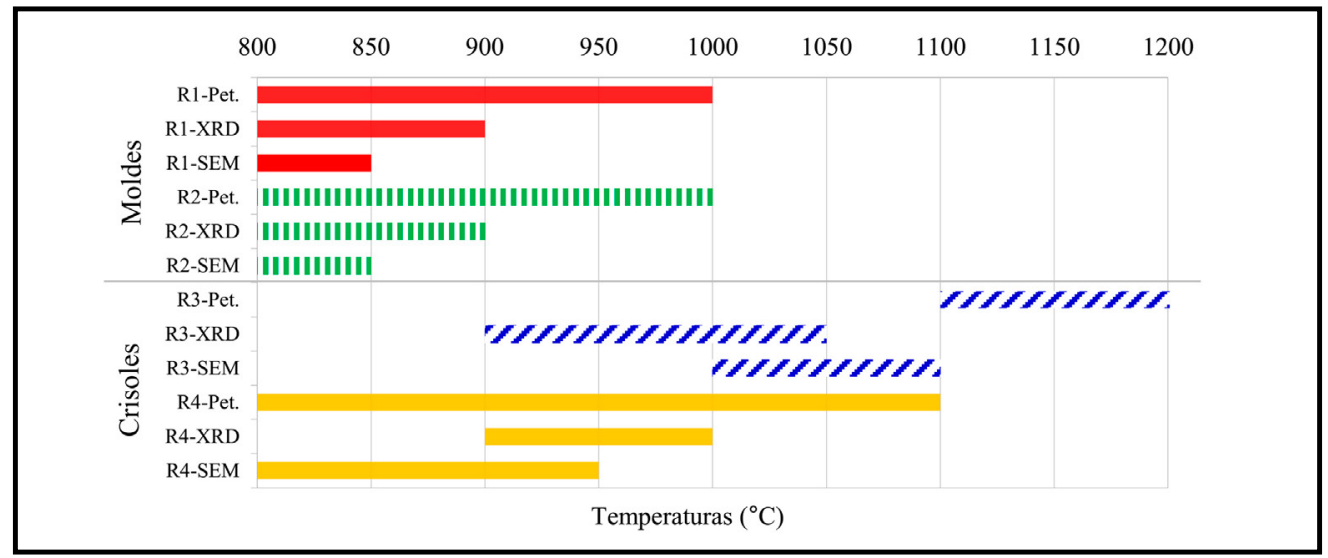

Figura 9. Resumen de las temperaturas de cocción de los cuerpos cerámicos en moldes y crisoles a partir de petrografía (Pet), XRD y SEM.

\section{La cobertura blanca}

Todos los moldes y crisoles están cubiertos por una cobertura blanca de alrededor de $800 \mu \mathrm{m}$ de espesor (Figura 10A), formada por granos angulares de textura esponjosa (Figura 10B). Los análisis microscópicos, químicos, XRD y FTIR indicaron que esta cobertura se compone de hidroxiapatita (HAp) alterada térmicamente, sugiriendo el uso de una pasta hecha de hueso puro molido aplicado sobre las piezas.

Los análisis químicos detectaron que el 86-97\% de la cobertura corresponde a fosfato de calcio, mientras que se detectó en bajas concentraciones de otros elementos como sílice, alúmina, óxido de hierro, óxido de magnesio, cloro, óxido de sodio y potasio $(<6,4 \%$; Tabla 7$)$. Los análisis en las inclusiones de hueso detectaron concentraciones menores de óxido de magnesio, sodio, potasio y cloro $(<0,5 \%)$, mientras que en el "cemento" o material aglutinante se observaron cantidades
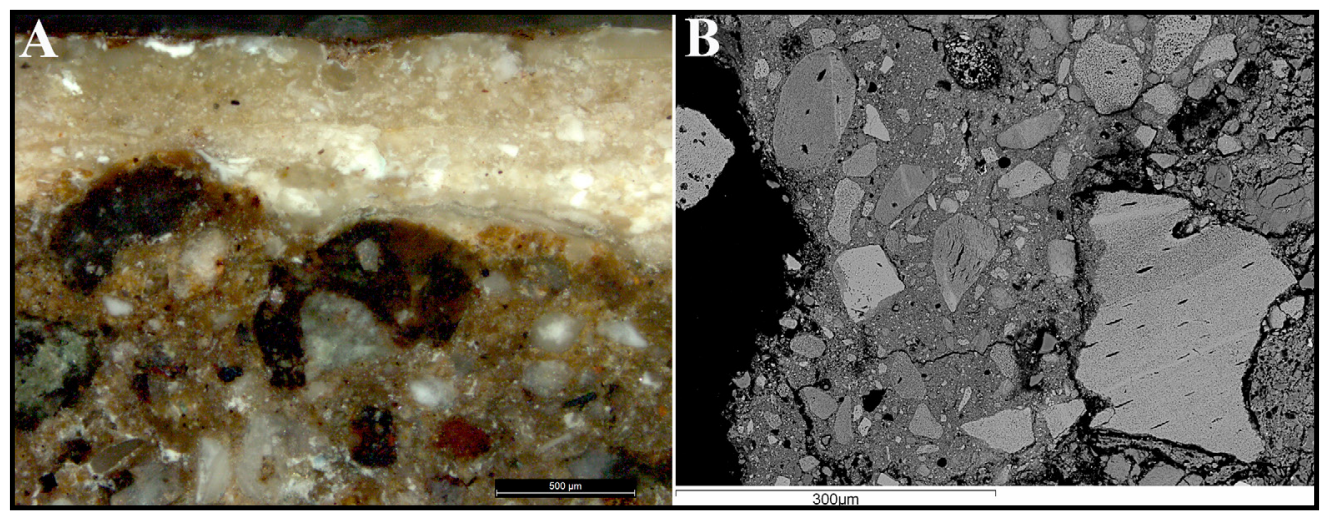

Figura 10. Detalle de la cobertura blanca. A) molde R2, imagen de microscopio óptico bajo polarización cruzada. El espesor promedio de esta cobertura en particular es de $602 \mu \mathrm{m}$. Imagen: 2,4 mm de ancho. B) molde R1, imagen de electrones retrodispersados (SEM). Imagen: $600 \mu \mathrm{m}$ de ancho (modificado de Plaza y Martinón-Torres, 2015, fig. 7). Nótese el detalle de las inclusiones irregulares y angulares de diferentes tamaños que componen la cobertura blanca. Su microestructura es comparable a fragmentos de hueso (Schiegl, Goldberg, Pfretzschner y Conrad, 2003; White, 2010). 
menores de alúmina y sílice $(<0,4 \%)$. Tanto en inclusiones como en el cemento, el porcentaje de fosfato de calcio fue cerca de $99 \%$, mientras que el ratio de $\mathrm{CaO} / \mathrm{P}_{2} \mathrm{O}_{5}$ fue estable en 1,3 . La baja concentración de otros elementos como alúmina y sílice indica que no se usaron otros aditivos o sustancias en la preparación de la cobertura. Por el contrario, sugiere que la pasta fue preparada usando fosfato de calcio puro, y la presencia de concentraciones menores de otros elementos se debe al contacto con la matriz cerámica. De hecho, la composición de esta pasta es muy similar a la de copelas hechas en pasta de hueso puro (ver Martinón-Torres et al., 2009; White, 2010).

Tabla 7. Composición química de la cobertura blanca obtenida por SEM-EDS.

\begin{tabular}{|c|c|c|c|c|c|c|c|c|c|c|c|}
\hline \multicolumn{12}{|c|}{ Composición química de la matriz arcillosa de moldes y crisoles, wt\% } \\
\hline & $\mathrm{Na}_{2} \mathrm{O}$ & $\mathrm{MgO}$ & $\mathrm{Al}_{2} \mathrm{O}_{3}$ & $\mathrm{SiO}_{2}$ & $\mathbf{P}_{2} \mathbf{O}_{5}$ & $\mathbf{C l}$ & $\mathrm{K}_{2} \mathrm{O}$ & $\mathrm{CaO}$ & $\mathrm{FeO}$ & Total $^{*}$ & $\begin{array}{l}\mathrm{CaO} / \\
\mathbf{P}_{2} \mathbf{O}_{5}\end{array}$ \\
\hline \multicolumn{12}{|c|}{ A) Composición química general de la cobertura blanca } \\
\hline $\begin{array}{l}\text { R1 - } \\
\text { Molde }\end{array}$ & 0,3 & 0,8 & 1,5 & 4,1 & 39,7 & 0,5 & nd & 52,6 & 0,5 & 63,2 & 1,3 \\
\hline $\begin{array}{l}\text { R2 - } \\
\text { Molde }\end{array}$ & 0,5 & 0,5 & 1,0 & 1,7 & 41,6 & 0,4 & nd & 54,2 & nd & 89,5 & 1,3 \\
\hline $\begin{array}{l}\text { R3 - } \\
\text { Crisol }\end{array}$ & 0,8 & 1,2 & 1,9 & 6,4 & 37,1 & 0,4 & 0,3 & 49,1 & 2,8 & 77,8 & 1,3 \\
\hline $\begin{array}{l}\text { R4 - } \\
\text { Crisol }\end{array}$ & 0,2 & 0,5 & 0,3 & 1,3 & 41,9 & 0,9 & nd & 54,9 & nd & 66,8 & 1,3 \\
\hline Promedio & 0,5 & 0,7 & 0,3 & 1,3 & 40,1 & 0,6 & 0,1 & 52,7 & 0,8 & - & 1,3 \\
\hline \multicolumn{12}{|c|}{ B) Composición de las inclusiones de hueso } \\
\hline $\begin{array}{l}\text { R1 - } \\
\text { Molde }\end{array}$ & nd & 0,3 & nd & nd & 42,7 & 0,2 & nd & 56,8 & nd & 85,2 & 1,3 \\
\hline $\begin{array}{l}\text { R2 - } \\
\text { Molde }\end{array}$ & 0,1 & 0,3 & nd & nd & 42,7 & 0,2 & nd & 56,7 & nd & 76,2 & 1,3 \\
\hline $\begin{array}{l}\text { R3 - } \\
\text { Crisol }\end{array}$ & 0,2 & 0,8 & nd & nd & 43,3 & 0,3 & 0,1 & 55,4 & nd & 89,8 & 1,3 \\
\hline $\begin{array}{c}\text { R4 - } \\
\text { Crisol }\end{array}$ & nd & 0,2 & nd & nd & 42,8 & 0,7 & nd & 56,3 & nd & 73,3 & 1,3 \\
\hline Promedio & 0,1 & 0,4 & - & - & 42,9 & 0,3 & 0,02 & 56,3 & - & - & 1,3 \\
\hline \multicolumn{12}{|c|}{ C) Composición del cemento o material aglutinante } \\
\hline $\begin{array}{l}\text { R1 - } \\
\text { Molde }\end{array}$ & nd & 0,4 & 0,3 & 0,5 & 42,6 & 0,6 & nd & 55,6 & nd & 60,1 & 1,3 \\
\hline $\begin{array}{l}\text { R2 - } \\
\text { Molde }\end{array}$ & nd & 0,5 & 1,0 & 0,6 & 42,1 & 0,9 & nd & 54,9 & nd & 82,8 & 1,3 \\
\hline $\begin{array}{l}\text { R3 - } \\
\text { Crisol }\end{array}$ & 0,1 & 0,5 & 0,2 & 0,4 & 42,6 & 0,5 & nd & 55,7 & nd & 74,7 & 1,3 \\
\hline $\begin{array}{c}\text { R4 - } \\
\text { Crisol }\end{array}$ & 0,2 & 0,6 & nd & nd & 42,7 & 1,1 & nd & 55,5 & nd & 62,5 & 1,3 \\
\hline Promedio & 0,1 & 0,6 & 0,4 & 0,4 & 42,5 & 0,7 & - & 55,4 & - & - & 1,3 \\
\hline
\end{tabular}

Nota: Las cifras están normalizadas al 100\%, pero se presentan los totales analíticos sin normalizar $\left(^{*}\right)$. La razón o ratio del óxido de calcio y fósforo es especificado en la última columna (modificado de Plaza y Martinón-Torres, 2015, tabla 5). 
Los patrones del XRD son consistentes con los estándares para los cristales de HAp (Figura 11 y Tabla 8). Sin embargo, en la naturaleza la HAp se presenta en forma mineral (geológico) o en los huesos (biológico: hueso animal o humano). Tanto la composición química como la XRD no permiten diferencias entre ambas HAp. Si bien la microestructura celular de las inclusiones sugiere la presencia de hueso, se procedió a hacer un análisis de espectroscopía infrarroja (FTIR) para identificar con certeza el origen geológico o biológico de la HAp. Esta técnica permitió además registrar las temperaturas a las que las coberturas fueron sometidas.

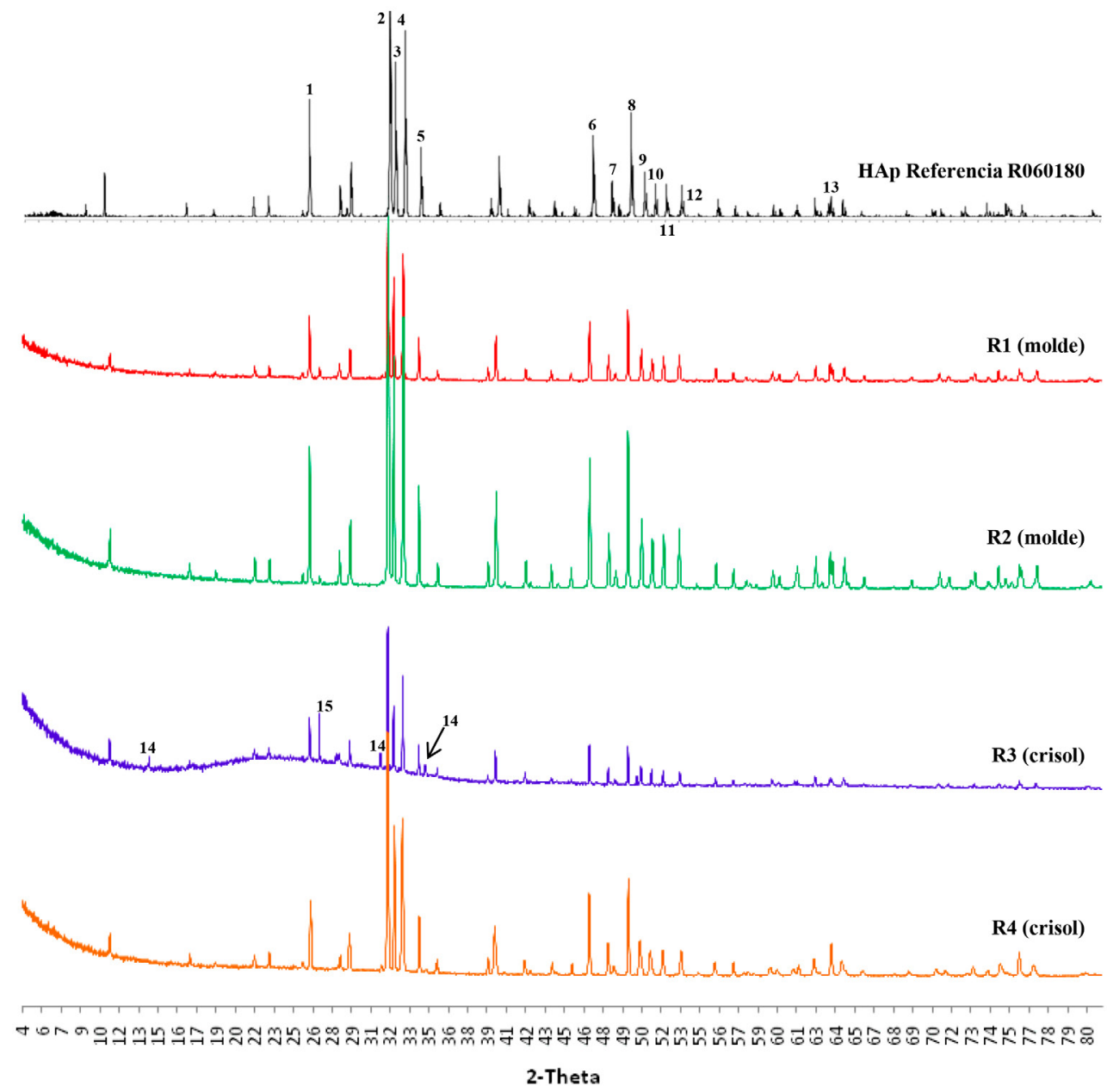

Figura 11. Patrón de XRD de la HAp geológica de referencia de Holly Springs, Georgia, EEUU (en negro; R060180, http://rruff.info/apatite) y las muestras de Los Nogales (en colores). La diferencia del patrón R3 se puede deber a la poca cantidad de muestra analizada, lo que genera una seńal de baja intensidad y mayor ruido, comparado con las otras muestras. También contiene whitlockita o $\beta$-TCP (14) y cuarzo (15). 
Tabla 8. Valores de los ángulos 2-Theta y planos cristalinos (1-13) más característicos del patrón de XRD de la HAp geológica y las muestras de Los Nogales (ver Figura 11).

\begin{tabular}{|c|c|c|c|c|c|c|c|}
\hline \multicolumn{3}{|c|}{ A. Hidroxiapatita (R060180) } & \multicolumn{5}{|c|}{ B. Cerámicas de Los Nogales } \\
\hline \multirow{2}{*}{ No } & \multirow{2}{*}{$\begin{array}{l}\text { Ángulo } \\
\text { (2-theta) }\end{array}$} & \multirow{2}{*}{ plano hkl } & \multicolumn{4}{|c|}{ Ángulo 2-theta } & \multirow{2}{*}{ Promedio } \\
\hline & & & R1 (molde) & R2 (molde) & R3 (crisol) & R4 (crisol) & \\
\hline 1 & 25,9 & 002 & 26,0 & 26,0 & 26,0 & 26,0 & 26,0 \\
\hline 2 & 31,8 & 211 & 31,8 & 31,9 & 31,8 & 31,8 & 31,8 \\
\hline 3 & 32,2 & 112 & 32,3 & 32,3 & 32,3 & 32,3 & 32,3 \\
\hline 4 & 32,9 & 300 & 33,0 & 33,0 & 32,9 & 32,9 & 33,0 \\
\hline 5 & 34,1 & 202 & 34,1 & 34,2 & 34,1 & 34,2 & 34,1 \\
\hline 6 & 46,7 & 222 & 46,7 & 46,7 & 46,7 & 46,7 & 46,7 \\
\hline 7 & 48,1 & 312 & 48,1 & 48,1 & 48,1 & 48,0 & 48,1 \\
\hline 8 & 49,5 & $213-123$ & 49,5 & 49,5 & 49,5 & 49,5 & 49,5 \\
\hline 9 & 50,5 & $231-321$ & 50,5 & 50,4 & 50,4 & 50,3 & 50,4 \\
\hline 10 & 51,3 & $140-410$ & 51,2 & 51,2 & 51,2 & 51,1 & 51,2 \\
\hline 11 & 52,1 & $402-303$ & 52,0 & 52,0 & 52,0 & 51,9 & 52,0 \\
\hline 12 & 53,2 & 004 & 53,1 & 53,2 & 53,2 & 53,3 & 53,2 \\
\hline \multirow[t]{2}{*}{13} & 64,0 & 304,0 & 63,7 & 63,7 & 63,7 & 63,7 & 63,7 \\
\hline & & $\begin{array}{l}\text { Dev. } \\
\text { Est. }(\sigma)\end{array}$ & 0,1 & 0,1 & 0,1 & 0,1 & 0,1 \\
\hline
\end{tabular}

Para confirmar la naturaleza biológica del polvo blanco, los espectros infrarrojos de las cerámicas técnicas de Los Nogales (Figura 12) fueron comparados con muestras experimentales de hueso calcinado y apatita mineral (Figura 13). Los resultados demuestran que casi todas las bandas de absorción de las cerámicas concuerdan con el espectro del hueso calcinado y difieren claramente de la apatita mineral, la cual presenta bandas que están ausentes en la apatita biológica y arqueológica. Es decir, el componente es claramente hueso.

Los espectros de las muestras arqueológicas presentaron todas las bandas de absorción características de los grupos funcionales de la HAp (ver Figura 12). Un peak agudo a los $\sim 3570$ y 


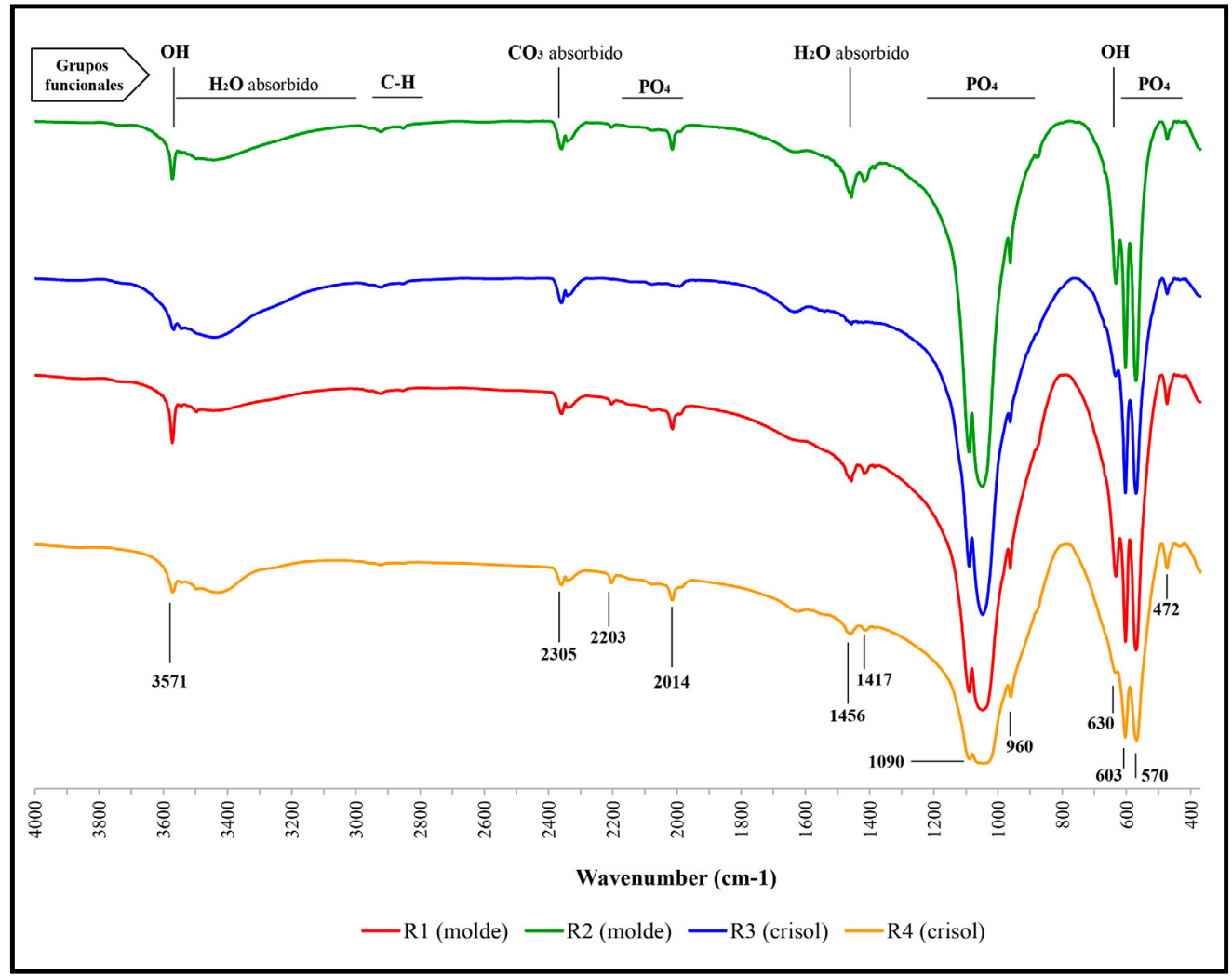

Figura 12. Espectros de FTIR de las cuatro muestras de Los Nogales señalando las bandas de absorción. Nótese que no todas las muestras presentan el mismo perfil. Sin embargo, una observación más detallada revela diferencias sutiles entre la apatita de los moldes y crisoles, relacionadas con la intensidad de las bandas

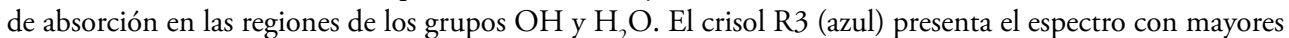
diferencias (modificado de Plaza y Martinón-Torres, 2015, fig. 8).

$630 \mathrm{~cm}^{-1}$ se correlaciona con la absorción de agua, representando los modos de estiramiento y vibracional de los grupos hidroxilo (OH-). El peak a los $630 \mathrm{~cm}^{-1}$ es importante ya que se forma cuando el mineral se somete a temperaturas sobre los $650^{\circ} \mathrm{C}$ y su presencia confirma que el hueso utilizado fue quemado (Koutsopoulos, 2002; 2007, 2005; Odriozola y MartínezBlanes, 2007; Arsad, Lee y Mara, 2011; Berzina-Cimdina y Borodajenko, 2012).

Al comparar los espectros, es posible reconocer diferencias entre la pasta de los moldes y crisoles. Investigaciones sobre el comportamiento térmico de la HAp señalan que a $700{ }^{\circ} \mathrm{C}$ las bandas de la región de absorción de agua se acentúan, pero sobre esta temperatura comienzan a decrecer en intensidad hasta que desaparecen a los $900^{\circ} \mathrm{C}$ (Koutsopoulos, 2002; BerzinaCimdina y Borodajenko, 2012). En este caso, los crisoles -en especial el R3- presentan peaks más débiles -a -3570 y $630 \mathrm{~cm}^{-1}$ - que los moldes. Esta diferencia estaría reflejando un mayor nivel de deshidratación, sugiriendo que la pasta de los crisoles fue sometida a más temperaturas que la de los moldes. Para confirmar esta propuesta, se realizaron experimentos de recocido de la pasta a $700^{\circ}-900^{\circ}$ y $1100^{\circ} \mathrm{C}^{8}$, y sus espectros FTIR fueron comparados con los originales

8 Para el experimento, la temperatura del horno se incrementó $200^{\circ} \mathrm{C}$ cada hora hasta alcanzar la temperatura máxima, la cual se mantuvo por una hora. 
de Los Nogales. Basados en la presencia/ausencia del peak $630 \mathrm{~cm}^{-1}$ y su intensidad, se establece que las coberturas de hueso fueron sometidas a temperaturas entre 700-900 ${ }^{\circ} \mathrm{C}$, mientras los moldes se acercaban a los $700^{\circ} \mathrm{C}$, los crisoles estaban cerca de los $900^{\circ} \mathrm{C}$, pero sin sobrepasar dicha temperatura (Figura 14).

De este modo, tanto la composición química, microestructura, XRD y FTIR indican el uso de una pasta de hueso molido calcinada que fue preparada sin otros excipientes. Esta fue aplicada a las cerámicas técnicas y fueron sometidas a temperaturas diferenciales, más bajas en los moldes y más altas en los crisoles. En ambos casos no sobrepasan los $900{ }^{\circ} \mathrm{C}$.

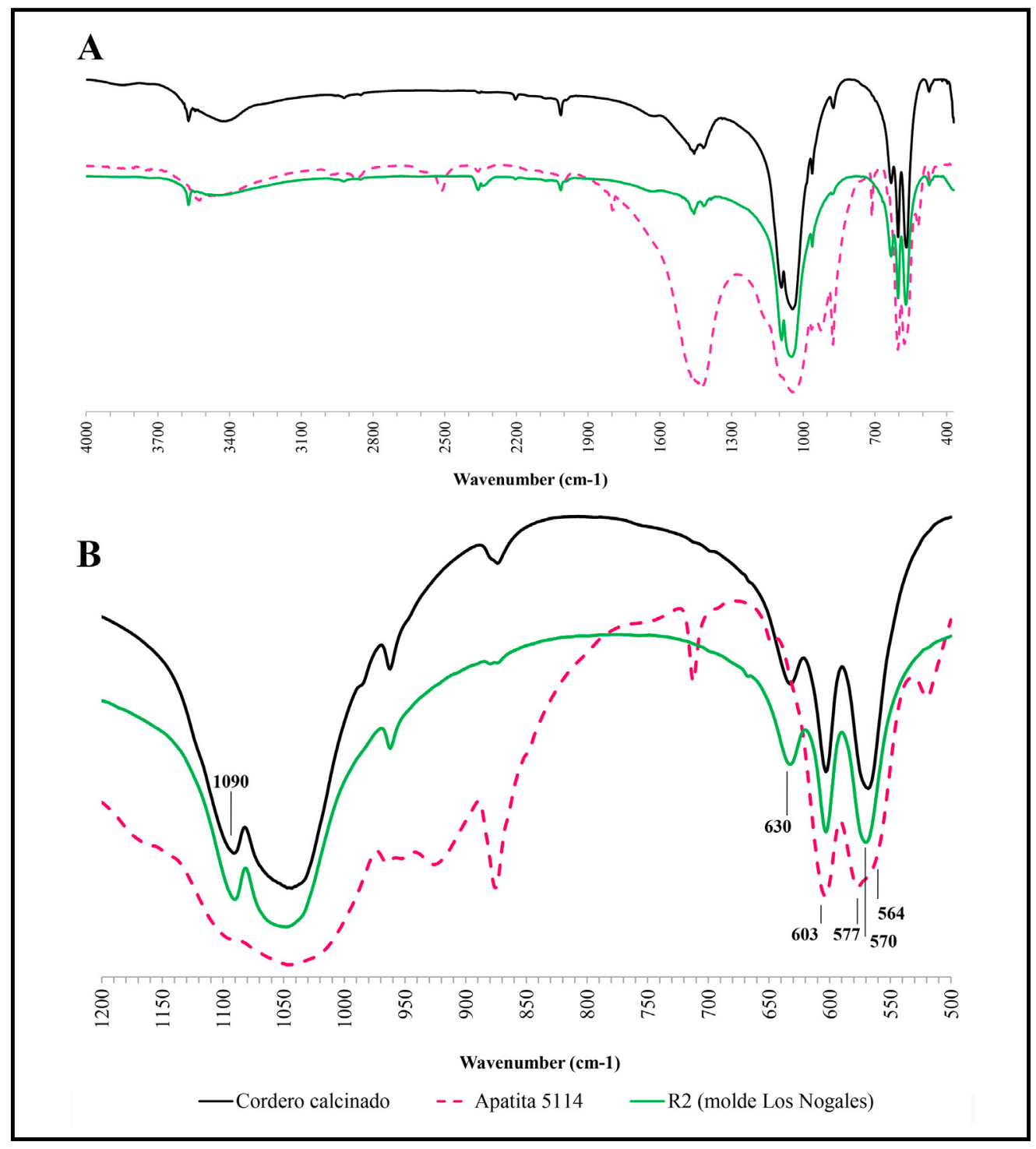

Figura 13. A) Espectros FTIR de hueso calcinado, apatita geológica y muestra arqueológica del molde R2. Nótese la similitud entre los espectros del molde R2 (verde) y el hueso calcinado (negro), comparado con la apatita geológica (rojo). B) Detalle de los espectros. Las bandas a 1090 y $630 \mathrm{~cm}-1$ son características de hueso calcinado. Según Odriozola y Hurtado (2005), el peak a -577 con un hombro a $564 \mathrm{~cm}-1$ es característico de la apatita geológica (modificado de Plaza y Martinón-Torres, 2015, fig. 9). 
Moldes

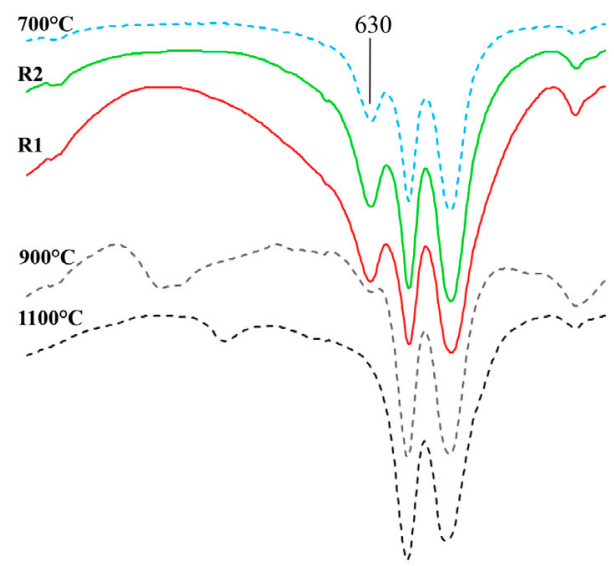

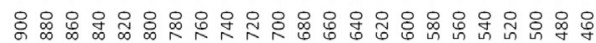

Wavenumber (cm-1)
Crisoles

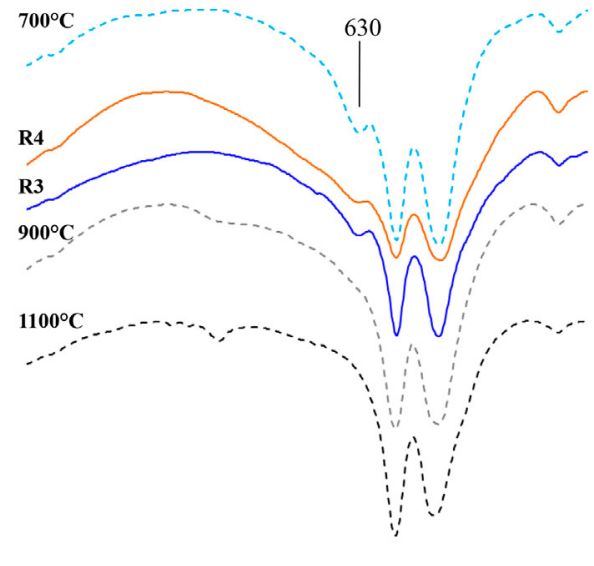

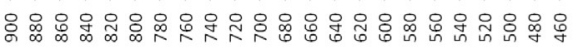

Wavenumber (cm-1)

Figura 14. Espectros FTIR de las muestras de HAp recocidas de la cobertura de los moldes (izquierda) y crisoles (derecha). Tomando en cuenta el desarrollo del peak a $630 \mathrm{~cm}-1$, el espectro de los moldes y crisoles sugiere el uso de temperaturas entre $700-900^{\circ} \mathrm{C}$.

\section{Evidencias de uso}

A simple vista ni los moldes ni crisoles presentaron restos visibles de metal, escoria o mineral adherido, sugiriendo que las piezas no fueron utilizadas. Esto se corrobora en las secciones anteriores, donde ni en el análisis de las pastas cerámicas (ver Tabla 4) ni de la cobertura de hueso (Tabla 7A) se detectaron elementos metálicos o pesados que correspondan a restos de metales procesados en los moldes o crisoles. Una alternativa que habría que explorar, es la posibilidad de que pasta de hueso se pueda desprender o raspar una vez que haya sido utilizada, llevándose con ella los residuos de metal. Dado que la capa de hueso es bastante inerte, debería ser fácil desprenderla de la cerámica propiamente dicha. Lamentablemente, por ahora no hay estudios experimentales que avalen esta alternativa.

Por otro lado, las temperaturas a las cuales las cerámicas y pasta de hueso fueron sometidas son temperaturas bajas para la fundición del cobre. El cobre en estado puro se fusiona a los 1083 ${ }^{\circ} \mathrm{C}$; si bien esta temperatura puede disminuir si se encuentra aleado con otros elementos, para mantener el metal en estado líquido se necesitarían temperaturas de alrededor de los $1100{ }^{\circ} \mathrm{C}$. Rangos entre $1050-1100{ }^{\circ} \mathrm{C}$ se registraron en crisoles con evidencias de uso del sitio Rincón Chico (L. R. González, 2004, pp. 93-94, 2010, p. 56), mientras que las piezas de Los Nogales fueron sometidas como máximo a $1050{ }^{\circ} \mathrm{C}$ y posiblemente a temperaturas más bajas.

Por tanto, los análisis de composición química y las estimaciones de las temperaturas utilizadas confirmarían las observaciones macroscópicas de que estas piezas no llegaron a ser utilizadas en actividades metalúrgicas. 


\section{Discusión}

\section{Crisoles y moldes de Los Nogales: decisiones de una tradición tecnológica}

El estudio arqueométrico de cuatro cerámicas metalúrgicas de Los Nogales permite proponer ciertos patrones relacionados con la manufactura de estos materiales que, si bien no son concluyentes, son indicaciones que futuros estudios podrían modificar y complementar. Teniendo esto en cuenta, se establece que los moldes y crisoles de Los Nogales fueron hechos a partir de la mezcla de gran cantidad de inclusiones de rocas ígneas bien seleccionadas (45-50\% vol) posiblemente obtenidas de depósitos aluviales locales-, combinadas con una pequeńa porción de arcilla del tipo esmectitas-montmorillonitas (35\% vol). A los moldes se le añadió adicionalmente hueso molido como antiplástico. Una vez formadas las piezas, los moldes fueron cocidos a temperaturas entre $800-850{ }^{\circ} \mathrm{C}$ bajo condiciones redox variables, mientras que los crisoles fueron cocidos en condiciones reductoras a $\geq 900^{\circ} \mathrm{C}$. Todas estas piezas fueron cubiertas por una pasta de hueso puro calcinado.

Debido a sus bajos niveles de alúmina y sus altos niveles alcalinos, la montmorillonita como arcilla es poco resistente a altas temperaturas, convirtiéndola en un material no adecuado para la formación de refractarios (Rice, 2005, p. 48). Es decir, no serían piezas refractarias propiamente tales, entendidas como materiales que resisten altas temperaturas sin alterarse. Sin embargo, los artesanos supieron cómo mejorar las propiedades de la arcilla mediante la adición de grandes cantidades de inclusiones relativamente gruesas como antiplástico, que permiten incrementar la refractariedad de la pasta (Hein et al., 2007) y hacerlas funcionales a sus propósitos.

Si bien la adición de gran cantidad de inclusiones gruesas es un rasgo común entre moldes y crisoles de otros sitios metalúrgicos del NOA y norte de Chile (Niemeyer, 1979; Campo, 2001; L. R. González, 2002a, 2010; Pradell, González y Gluzman, 2010), el uso de hueso como antiplástico en la manufactura de las cerámicas técnicas parece ser un elemento novedoso y relevante. Agregar hueso molido a la pasta cerámica presenta ciertas ventajas. Por ejemplo, previene la formación de fisuras durante la etapa de secado y facilita la manipulación de la arcilla (Walter, Paine y Horni, 2004). Tiene coeficientes de expansión similares a los de la cerámica, generando piezas más resistentes y flexibles a la vez (Stilborg, 2001). Ya en el siglo XVI, el metalurgo italiano Biringuccio indica que para producir "crisoles resistentes" se debe usar ceniza de cuernos de carnero y fragmentos de rocas resistentes (Smith y Teach-Gnudi 1990, p. 391, en Karageorghis y Kassianidou, 1999, p. 181). Además, el hueso es químicamente inerte, por lo cual no reacciona con el óxido de los metales, pero sí los absorbe mediante acción capilar, razón por la cual ha sido tradicionalmente usado en actividades metalúrgicas como la copelación (Martinón-Torres, Thomas, Rehren y Mongiatti, 2008; Martinón-Torres et al., 2009; White, 2010).

Estas características sugieren que el uso de hueso como antiplástico podría mejorar la refractariedad y manipulación de la pasta. Lo interesante en este caso es que son los moldes y no los crisoles los que contienen hueso. Tecnológicamente hablando, son los crisoles los que se someten a condiciones térmicas y químicas mucho más agresivas que los moldes, pero los artesanos agregaron hueso molido solo a los moldes. ¿Cómo se puede entender esta decisión? Si consideramos que los moldes de Los Nogales evidencian temperaturas de cocción relativamente bajas produciendo una cerámica quebradiza, podríamos sugerir que -más que para incrementar 
la refractariedad- el hueso se agregó para mejorar la manipulación y propiedades de la pasta antes y después de su cocción, minimizando el grado de contracción del molde, el cual podría afectar las formas que son diseñadas en él. En este caso, el rol central en el incremento de la refractariedad de estas cerámicas recaería en la pasta de hueso aplicada superficialmente, la cual protegería la cerámica de la acción del metal caliente (L. R. González, 2010; Hein et al., 2015; Gluzman, 2017; Hein, Gluzman y Kilikoglou, 2018). Por último, no podemos descartar que el uso de hueso molido como desgrasante tenga una explicación más allá de la tecnológica o funcional y que su aplicación responda a un ámbito ritual o ceremonial, más difícil para nosotros de aprehender.

En relación a la pasta de hueso que cubre las piezas cerámicas, se plantean diversas propiedades, algunas relacionadas con la mejora de las cerámicas mismas y otras, con el metal producido. Pero en general, se puede decir que esta cobertura ayudó a producir cerámicas más resistentes. Por ejemplo, se destacan sus propiedades refractarias para proteger las cerámicas de la acción térmica y química del metal caliente y para controlar mejor el grado de enfriamiento del metal (Niemeyer, 1979; Raffino et al., 1996; L. R. González, 1997, 2010; Zori et al., 2012; Hein et al., 2015, 2018; Gluzman, 2017). Generaría mayor resistencia en las cerámicas, ya que al secarse la pasta de hueso se vuelve dura y firme (L. R. González, 1997, 2010); permitiría alisar las paredes de los refractarios mejorando el flujo del metal y evitando que este se adhiera a las paredes (Niemeyer, 1979; L. R. González, 1997, 2010) o facilitando el desmolde de las piezas fundidas (Raffino et al., 1996; Pifferetti, 2004). Otros autores plantean un uso como desoxidante, removiendo el oxígeno libre o combinado del cobre o bronce, mejorando la capacidad de fusión y dureza del metal (Karageorghis y Kassianidou, 1999; Zori et al., 2012); esto también puede producir una ligera contracción del metal durante el enfriamiento, facilitando su remoción del molde (Zori et al., 2012). Finalmente, las cerámicas metalúrgicas de Rincón Chico 15, en el Noroeste Argentino, muestran varias capas de esta pasta de hueso separando diferentes eventos de fundición (L. R. González, 2010; Hein et al., 2015), indicando que esta cobertura permitió en muchos casos la reutilización de las piezas (Plaza, 2013).

En relación a la receta utilizada, la pasta de hueso utilizada en Los Nogales es hueso puro, sin aditivos. En Rincón Chico 15 y Tarapacá Viejo se reportan composiciones similares (L. R. González, 2010; Zori et al., 2012), pero no es la única receta. La cobertura blanca del crisol de Carrizalillo Grande estaba compuesta por larnita, un silicato de calcio (Niemeyer, 1979), mientras que en Quillay Wayra, la pasta blanca corresponde a una mezcla de compuestos de calcio como larnita, oxalato de calcio, HAp y otros silicatos de calcio (Raffino et al., 1996). El uso de recetas diferentes sugiere, por un lado, una variabilidad a nivel de tradiciones tecnológicas; y por otro, un conocimiento compartido según el cual los artesanos sabían qué propiedades mejorar en las pastas cerámicas para que funcionaran como crisoles o moldes y cómo utilizar los distintos materiales disponibles para producir resultados similares.

En general, el ratio de $\mathrm{CaO} / \mathrm{P}_{2} \mathrm{O}_{5}$ en los huesos puede variar levemente entre especies y entre ciertos huesos de un mismo animal o humano (Martinón-Torres et al., 2009). En este caso, tanto las inclusiones de la cobertura externa como aquellas usadas como antiplástico tienen un ratio de 1,3 y comparten además la composición química, sugiriendo que se utilizó la misma fuente de hueso en ambos casos. Esta conexión es interesante, ya que vincula tecnológicamente los crisoles y moldes a pesar de que los primeros no contienen hueso como antiplástico, respaldando las similitudes observadas en los análisis petrográficos y químicos. 
Considerando que las cerámicas metalúrgicas no fueron utilizadas, se destacan dos situaciones en relación a las temperaturas a las que la cobertura de hueso y el cuerpo cerámico fueron expuestos. Primero, en ambos casos se observan rangos diferentes para moldes y crisoles. Segundo, estos rangos son siempre menores para los moldes y más altos para los crisoles. Entre los $700-900{ }^{\circ} \mathrm{C}$, las coberturas de los moldes aparecen cerca de los $700{ }^{\circ} \mathrm{C}$, lo que coincide con las temperaturas de cocción de los cuerpos alrededor de los $800-850^{\circ} \mathrm{C}$. La cobertura de los crisoles, en cambio, sugiere temperaturas cercanas a $900{ }^{\circ} \mathrm{C}$, lo que coincide con el rango térmico del crisol R4 $\left(900-950{ }^{\circ} \mathrm{C}\right)$, pero son temperaturas bajas para el crisol R3 que indica valores sobre los $1000^{\circ} \mathrm{C}$.

A pesar de esta discrepancia, es claro que ambas partes (coberturas y cuerpos) siguen los mismos patrones, sugiriendo que la pasta de hueso fue aplicada antes de la cocción de las cerámicas. Si las cerámicas y coberturas se hubiesen cocido por separado y la pasta hubiese sido aplicada posteriormente, las temperaturas de las coberturas de hueso serían todas iguales o todas distintas, dependiendo de si fueron producidas o no en un mismo evento. Pero el hecho de que las coberturas muestran rangos distintos asociados a las temperaturas de cocción de las cerámicas es indicativo de que ambos eventos están relacionados. Basados en esto, se puede asumir que el hueso utilizado en la preparación de la pasta no fue necesariamente calcinado a altas temperaturas antes de su aplicación. Un dato interesante que apoya esta hipótesis es la evidencia de molienda de hueso que se registra en el sitio Los Corrales-1 en Tucumán, Argentina (Babot y Apella, 2003). En este sitio se identificaron restos de maíz y hueso en una piedra de moler (ver Figura 2). Los análisis de XRD, FTIR y cromatografía de gas revelaron que los residuos de hueso de Los Corrales-1 contenían lípidos de origen animal, indicando que el hueso molido fue quemado a bajas temperaturas antes de ser molido (Babot y Apella, 2003). Es probable, entonces, que el hueso utilizado para manufacturar los crisoles y moldes fuera procesado y molido después de una cocción inicial a bajas temperaturas (p.e., cocinado), posteriormente tamizado y mezclado con agua y aplicado a las cerámicas, las cuales fueron finalmente cocidas.

\section{Los Nogales dentro del contexto regional}

Como mencionamos al principio, crisoles perforados como los de Los Nogales se registran en otros sitios en Chile y Argentina, todos asociados a actividades metalúrgicas (ver Figura 2): Rincón Chico y Quillay Wayras en el NOA; Pachimoco, Angualasto y Barrealito en el centro-oeste argentino; Tarapacá Viejo, Carrizalillo Grande, Iglesia Colorada y posiblemente Viña del Cerro en el norte de Chile (Niemeyer, 1979; L. R. González, 1997; Zori et al., 2012; Zori, 2019).

Por la presencia del agujero se descarta su uso durante la etapa de fundición del mineral en metal. Más bien se ha sugerido que estos crisoles fueron utilizados para acumular el metal ya fundido y aleado, el cual sería distribuido en distintos moldes (Niemeyer, 1979; L. R. González, 1997). A partir de un tapón ajustado por el interior o exterior, se regularía el paso del metal (L. R. González, 1997; Pifferetti, 2004). Manipular estas piezas (crisol y tapón) no sería fácil, ya que algunos son recipientes relativamente pesados ${ }^{9}$ (desde 0,7-3 kg aprox., ver Anexo 2), que transportan metal a altas temperaturas. Según González y Gluzman (2009), su uso involucraría un alto grado de experticia y conocimiento técnico tanto de las propiedades del metal como de la cerámica, para evitar la pérdida, oxidación y enfriamiento del metal producido.

9 Hemos podido calcular el volumen de nueve crisoles de Chile y Argentina, que van entre $80-335 \mathrm{~cm}^{3}$, lo cual podría contener entre 0,7 y $3 \mathrm{~kg}$ de metal. Detalles en Anexo 2 . 
Si bien González y Gluzman (2009) lo han descrito como un sistema complejo y complicado de utilizar, sería una solución eficiente que permite liberar el volumen de metal producido del metal realmente utilizado, y llenar múltiples moldes de una sola vez (L. R. González, 1997), al tiempo que evita que la escoria que flota en superficie sea arrastrada dentro del molde actuando como una "trampa de escoria" (Pifferetti, 2004). Soluciones similares, con agujeros cerca de la base, se reportan en Egipto (ver pieza UC8901, Petrie Museum). En América, esta tecnología utilizando los crisoles perforados corresponde a una tradición metalúrgica originada en el NOA y asociada hasta ahora al período de influencia incaica (L. R. González, 1997, 2010).

La cobertura de pasta de hueso también es un rasgo característico de la metalurgia del NOA, pero presenta antecedentes más tempranos. Las primeras evidencias se encuentran en la fase La Aguada (500-900 DC), asociadas al comienzo del uso del bronce y el desarrollo de complejas técnicas de fundido y modelado de piezas (L. R. González, 1997, 2002a, 2002b, 2004, 2010). En Chile, tanto la aparición de los crisoles perforados como de cerámicas metalúrgicas cubiertas con pastas calcáreas está relacionada con la expansión del Tawantinsuyu, y serían los incas quienes habrían introducido esta tecnología en sitios como Tarapacá Viejo y Viña del Cerro (L. R. González, 1997, 2010; Zori et al., 2012; Zori, 2019). Dada la complejidad del sistema, se plantea que esta difusión tecnológica pudo incluir también el movimiento de expertos metalurgos y no solo de ideas o materiales (L. R. González, 2010).

Si bien las cerámicas de Los Nogales no llegaron a ser utilizadas en actividades metalúrgicas (lo cual genera múltiples preguntas), sus similitudes con piezas encontradas en otros sitios metalúrgicos indican que estamos claramente frente a equipamiento para metalurgistas. Las piezas analizadas comparten ciertas características con las cerámicas metalúrgicas del período, como la morfología, el uso de un alto porcentaje de antiplásticos y el bajo volumen de arcilla, las paredes gruesas y la aplicación de una cobertura calcárea interna y externa. Sin embargo esta tecnología no es estandarizada, ya que existe gran variación en las dimensiones de las piezas, en la forma y ubicación del agujero, el uso del tapón (interno o externo), la receta de la cobertura y los sistemas de sujeción (L. R. González, 1997). La aplicación de hueso molido como antiplástico en moldes aparece hasta ahora como una solución tecnológica única de las piezas de Los Nogales; cerámicas metalúrgicas de otros sitios analizados a la fecha no reportan este tipo de material (Campo, 2001; L. R. González, 2002a, 2010; Pradell et al., 2010). Sería interesante explorar a futuro si el uso de hueso como antiplástico se repite en cerámicas domésticas o de otro tipo.

A partir de lo anterior, es posible plantear que las cerámicas metalúrgicas de Los Nogales vinculan este sitio a una tradición metalúrgica mayor, con base en el NOA y expandida en Chile y el centro-oeste argentino por el Tawantinsuyu (L. R. González, 1997). En este sentido, Los Nogales representaría hasta ahora una zona marginal, al sur del límite meridional de lo que Raffino y colegas consideraban el "núcleo minero-metalúrgico de los Andes sur" (1996, p. 65), marcando un límite hasta donde esta tecnología se habría expandido, pero no necesariamente implementado.

Es interesante notar que la intervención incaica en Los Nogales no sigue el patrón observado para estos casos. En general se observa una elección del Tawantinsuyu por centros metalúrgicos o mineros ya establecidos, como Rincón Chico (L. R. González, 2010), Tarapacá Viejo (Zori et al., 2012) y El Abra (Salazar y Salinas, 2008). En ellos el Estado se centró en reorganizar e incrementar la escala de producción, introduciendo algunas variaciones como la huayra, 
pero sin modificar los estilos tecnológicos previos. Esto contrasta con las características de Los Nogales, el cual se ubica en un sector que carece de una tradición metalúrgica anterior (Plaza, 2010, p. 17), correspondiendo a un sitio habitacional local del PT sin arquitectura y sin evidencias materiales asociadas al inca (Pavlovic, 2010); excepto por las cerámicas metalúrgicas y las dos piezas de metal asociadas al entierro de un individuo - una de ellas hecha en bronce de $11 \%$ de estańo (Plaza y Martinón-Torres, 2015) - que estarían siendo introducidas por el Tawantinsuyu. En este sentido, Los Nogales podría evidenciar una nueva forma de interacción del Tawantinsuyu, introduciendo una nueva tradición tecnológica ya establecida en sitios incaicos del norte de Chile y NOA, a través de grupos locales que no contaban con una tradición metalúrgica previa (Plaza y Martinón-Torres, 2015).

\section{Los Nogales dentro del contexto local}

¿Cómo entender la presencia de esta tradición tecnológica en el desarrollo cultural del valle del Aconcagua? Como mencionamos en la introducción, en la cuenca del Aconcagua las piezas de metal se concentran en sitios incaicos, los cuales contienen evidencias cerámicas diaguita-inca. En cuanto a las pocas evidencias metalúrgicas -escorias y cerámica con escorias adheridas en El Castillo-, también se encuentran en un sitio con influencia diaguita-inca (Sánchez, 2002). En relación al estilo y técnicas de manufactura de las piezas metálicas encontradas en el valle, se observa una fuerte relación con la metalurgia diaguita. Estas comparten materias primas (p.e., cobre sin alear), diseńos, categorías de objetos (como los aros) y técnicas de formado que se encuentran en el repertorio cultural diaguita desde el PIT (Plaza, 2010, p. 84; Latorre y López, 2011). Estas características sugieren que gran parte de la metalurgia de la cuenca del Aconcagua fue adquirida o manufacturada empleando una tradición metalúrgica diaguita (Plaza, 2010, p. 114; Plaza y Martinón-Torres, 2015). Dado lo anterior, la pregunta es, ¿̨por qué las cerámicas técnicas se encuentran precisamente en Los Nogales y no en un sitio incaico, que es donde se concentra la mayor parte de las piezas de metal en el valle? O en otras palabras, ¿por qué una nueva tecnología metalúrgica introducida por el Tawantinsuyu aparece en un sitio local, en un área sin una tradición metalúrgica previa y no en sitios que se relacionan con grupos que ya se asocian con tradiciones metalúrgicas anteriores?

En su estudio sobre la metalurgia diaguita del norte semiárido, Latorre identifica una conducta conservadora en relación a la tecnología metalúrgica, observando una clara continuidad tecnológica y estilística desde Ánimas (700 DC), con poca variación incluso durante el PT. Es decir, se están usando y haciendo las mismas piezas a lo largo del tiempo, introduciendo pocas variaciones tanto a nivel estilístico como técnico ${ }^{10}$ (2009, pp. 94-95). Considerando esto, es posible proponer que el uso y producción de las piezas hechas bajo la tradición metalúrgica diaguita del valle del Aconcagua también reflejan una actitud conservadora, eligiendo piezas con antecedentes culturales conocidos y hechos en técnicas y metales tradicionales diaguitas. En este sentido, un intento por parte del Tawantinsuyu de introducir nuevas tecnologías metalúrgicas podría no ser muy eficaz; mientras que las comunidades locales del valle del Aconcagua, que no contaban con una tradición metalúrgica previa, podrían ser más receptivas a la introducción de nuevas tecnologías, precisamente por no tener una tradición establecida. Adicionalmente, se detectaron en Los Nogales relaciones con la cultura Aconcagua del valle del Maipo-Mapocho. La cultura Aconcagua utilizó y produjo metal en una escala pequeña

10 Este comportamiento "conservador” estaría dado solo para la tecnología metalúrgica, ya que en cerámica se observa lo contrario, una clara integración de aspectos tecnológicos y estilísticos entre lo diaguita y lo inca (Latorre 2009, p. 94). 
durante el PIT (Campbell y Latorre, 2003; Plaza, 2010). Si bien en el valle del Aconcagua no existe una tradición metalúrgica durante el PIT, las relaciones con la cultura Aconcagua podrían haber facilitado la adopción de esta tecnología, aportando un simbolismo, conocimiento e ideas relacionados con el trabajo y uso del metal.

Este panorama concuerda con lo propuesto por Pavlovic y colegas (Pavlovic, Troncoso, González y Sánchez, 2004; Pavlovic, Troncoso, Sánchez y Pascual, 2012; Pavlovic et al., 2019; Pavlovic, Sánchez, Pascual y Martínez, en prensa), quienes plantean que las evidencias incas en Chile central no respaldan la idea de una conquista coercitiva; más bien indican que se trató de un fenómeno basado en la difusión y transmisión de la ideología y principios incas, los cuales fueron aceptados y adoptados de forma distinta entre la población local, produciendo diferentes niveles de transformación e integración con el Tawantinsuyu (Pavlovic et al., 2012, p. 566). En este proceso, los cambios y continuidades en el uso y producción de la cultura material revelarían en parte estas relaciones, actuando como indicadores ya sea de una resistencia cultural o de distintas estrategias aplicadas por los incas para generar un nuevo orden (L. R. González y Tarragó, 2004).

En el caso del valle del Aconcagua, la potencial introducción de una nueva forma de trabajar el metal observada en Los Nogales sería reflejo de este dominio inca culturalmente mediado, sugiriendo una adaptación a las condiciones propias de la cultura local del PT, relacionada posiblemente con su grado de aceptación hacia nuevas tecnologías. Al mismo tiempo, este nivel de interacción entre la cultura local e inca es novedosa en el área, ya que en general no se registran materiales incaicos en sitios locales, sugiriendo que el Tawantinsuyu no intervino los asentamientos de las comunidades locales, sino más bien se asentaron en lugares que no fueron utilizados previamente, reordenando y resignificando el espacio a nivel de valle (Sánchez, 2004; Pavlovic et al., 2012). Así, Los Nogales se presenta como una excepción, donde la influencia del Tawantinsuyu se observa de forma diferente en la presencia de nuevas materialidades, como metales y cerámicas metalúrgicas. Finalmente, la presencia de una tecnología en Chile central con raíces en el NOA demuestra lo complejas y amplias que son las redes de interacción de la época.

\section{Conclusiones}

El estudio tecnológico de las cerámicas metalúrgicas de Los Nogales ha permitido caracterizar una serie de materiales relativamente escasos y que raramente se encuentran sin uso. Aplicando distintos estudios, hemos propuesto recetas y formas de hacer que dan cuenta de conocimientos específicos de los artesanos que las manufacturaron. Se identificaron las materias primas, atmósferas y temperaturas de cocción utilizadas, además de detectar el uso de hueso molido para cubrir las piezas y como antiplástico, siendo este último un aspecto único del valle del Aconcagua. En su conjunto, todos estos elementos permitieron producir piezas resistentes y eficientes para el trabajo metalúrgico que, sin embargo, no fueron utilizadas.

Esta tecnología metalúrgica se puede rastrear hasta el NOA, donde varios de estos elementos se encuentran presentes desde el Período Medio (400-900 DC), como es la pasta de hueso y la base perforada, pero que fue introducida en Chile durante la expansión del Tawantinsuyu. Dentro del contexto del valle del Aconcagua, la aparición de dicha tecnología en un sitio de carácter local sugiere que la expansión inca fue compleja y variada. Por una parte, el Tawantinsuyu se adaptó a las distintas condiciones locales, lo que permitió -por ejemplo-la continuidad 
de la tecnología metalúrgica diaguita en otras partes del valle. Por otra parte, las comunidades locales también reaccionaron a estas nuevas tecnologías. En el caso del valle del Aconcagua, proponemos que un factor relevante pudo ser la falta de una tradición metalúrgica previa, que permitió a las poblaciones locales ser más receptivas a las nuevas tecnologías que el Tawantinsuyu estaba incorporando y haciendo circular.

Quedan, sin embargo, muchas dudas sobre la presencia de estas piezas en Los Nogales. ¿Por qué estas cerámicas metalúrgicas no fueron utilizadas? ¿Cómo se relacionan estas piezas con el personaje enterrado con objetos de bronce? ¿Representarían el movimiento de materiales o artesanos metalurgistas? ¿Se trataría de un intento por introducir una nueva tecnología metalúrgica en el valle, truncado por la llegada de los españoles? Esperamos que nuevos hallazgos y más estudios sobre objetos de metal en el valle del Aconcagua vayan aclarando y dando más pistas sobre el desarrollo y la variabilidad de la metalurgia del área.

\section{Agradecimientos}

Esta investigación se realizó en el marco de la tesis de Magíster en Ciencias de MTP, en la University College London (UCL). Agradecemos a todo el equipo del Wolfson Archaeological Science Laboratories del UCL Institute of Archaeology, por su guía y apoyo. Al Gobierno de Chile, Becas Chile CONICYT y proyecto ANID 3200229 por el apoyo económico a MTP. Gracias a Ian Wood, Geraldine Gluzman, Luis González, Carlos Odriozola, Rodrigo Riveros, Andrés Troncoso y al Consejo de Monumentos Nacionales de Chile por sus invaluables comentarios y ayuda en distintas etapas de esta investigación. Agradecemos a las y los evaluadores anónimos que ayudaron a mejorar el manuscrito inicial.

\section{Referencias citadas}

Arsad, M. S. M., Lee, P. M. y Mara, U. T. (2011). Synthesis and Characterization of Hydroxyapatite Nanoparticles and $\beta$-TCP Particles, 7, 184-188.

Babot, M. del P. y Apella, M. C. (2003). Maize and bone: Residues of grinding in northwestern Argentina. Archaeometry, 1(45), 121-132.

Bárcena, R. (2001). Los objetos metálicos de la ofrenda ritual del Cerro Aconcagua. En Schobinger, J. (Ed.). El santuario incaico del cerro Aconcagua (pp. 281-301). Mendoza: EDIUNC Universidad Nacional de Cuyo.

Berzina-Cimdina, L. y Borodajenko, N. (2012). Research of Calcium Phosphates Using Fourier Transform Infrared Spectroscopy. En Theophanides, T. (Ed.). Infrared Spectroscopy - Materials Science, Engineering and Technology (pp. 123-148). Rijeka: Web of Science. https://www.intechopen.com/books/infraredspectroscopy-materials-science-engineering-and-technology/research-of-calcium-phosphates-using-fourier-transformation-infrared-spectroscopy

Cabeza, Á. (1986). El santuario de altura Cerro El Plomo. Tesis de grado para optar al título de Licenciado en Arqueología y Prehistoria de Chile. Departamento de Antropología, Universidad de Chile. Memoria Chilena. http://www.memoriachilena.gob.cl/602/w3-article-336337.html

Campbell, R. y Latorre, E. (2003). Rescatando una materialidad olvidada: Síntesis, problemáticas y perspectivas en torno al trabajo prehispánico de metales de Chile Central. Boletín de la Sociedad Chilena de Arqueología, 35/36, 47-61. 
Campo, P. (2001). Interpretando los fragmentos de refractarios del poblado prehispánico de Rincón Chico, Catamarca. En Actas del XIV Congreso de Arqueología Argentina, (pp. 15-24). Universidad Nacional de Rosario.

Cantarutti, G. E. (2013). Mining Under Inca Rule in North-Central Chile: The Los Infieles Mining Complex. En Tripcevich, N. y Vaughn, K. J. (Eds.). Mining and Quarrying in the Ancient Andes: Sociopolitical, Economic, and Symbolic Dimensions (pp. 185-211). New York: Springer. https://doi. org/10.1007/978-1-4614-5200-3_9

Cole, S. (1935). The conversion of quartz into cristobalite below $1000^{\circ} \mathrm{c}$, and some properties of the cristobalite formed. Journal of the American Ceramic Society, 18(1-12), 149-154.

Dávila, C. (2010). Análisis Cerámico del Sitio Los Nogales. Comuna de San Esteban, V región. Informe de Análisis Cerámico inédito, Proyecto Fondecyt 1090680. Ms.

Debenedetti, S. (1916). Investigaciones arqueológicas en los valles preandinos de la provincia de San Juan. Revista de la Universidad de Buenos Aires, 15, 122-167.

Durán, E., Rodríguez, A. y González, C. (2000). El Coligüe: Un asentamiento incaizado (Cuesta de Chacabuco, Chile Central). En Actas del XIV Congreso Nacional de Arqueología Chilena, Copiapó 1997, 2 (pp. 223-250). Editores Tamarugal.

Ewbank, T. (1855). Appenix E. A description of the Indian Antiquities brought from Chile and Peru, by the U.S. Naval Astronomical Expedition. En Gillis, J. M. (Ed.). The U.S. Naval Astronomical Expedition to the Soythern Hemisphere during the years 1849-'50-'51-'52. Vol. II (pp. 110-150). Washington DC: Harvard College Library.

Figueroa-Larre, V., Mille, B., Salazar, D., Berenguer, J., Menzies, A., Sapiains, P., Cifuentes, A. y Delphine, J. (2018). A major prehispanic copper production center identified at Collahuasi, southern Tarapacá Altiplano (Chile). Chungara. Revista de Antropologia Chilena, 50(4), 557-575.

Fonck, F. (1910). La rejión pre-histórica de Quilpué y su relación con la de Tiahuanacu. Estudio arqueológico basado en la colección del autor exhibida en la Esposición Histórica del Centenario. Valparaíso: Sociedad Imprenta y Litografía Universo.

Gajardo-Tobar, R. y Silva, J. (1970). Notas sobre arqueología de Quillota. Excavaciones en el estadio. Anales del Museo de Historia Natural de Valparaíso, 3, 203-236.

Garceau, C., MacRostie, V., Labarca, R., Rivera, F. y Stehberg, R. (2010). Investigación arqueológica en el sitio Tambo Ojos de Agua. Cordillera de Aconcagua. En Actas del XVII Congreso Nacional de Arqueología Chilena, Valdivia 2006, 1 (pp. 351-363). Sociedad Chilena de Arqueología.

Gluzman, G. (2017). Caracterización morfológica y funcional de moldes y crisoles del sitio 15 de Rincón Chico, Provincia de Catamarca. En Rocchietti, A., Ribero, F. y Reinoso, D. (Eds.). Investigaciones arqueométricas: Técnicas y procesos (pp. 77-89) Buenos Aires: Aspha.

González, C. (1998). ¿Funebria incaica o de yanaconas en Chile Central? La problemática de las adscripciones tempo-culturales. Boletín Sociedad Chilena de Arqueología, 25, 31-36.

González, L. R. (1997). Cuerpos ardientes. Interacción surandina y tecnología metalúrgica. Estudios Atacameños, 14, 175-188. 
González, L. R. (1998). Bronces bajo el sol. Metalurgia prehispánica en el noroeste Argentino. Etnologiska Studier, 43.

González, L. R. (2002a). A sangre y fuego. Nuevos datos sobre la metalurgia Aguada. Estudios Atacameños, 24, 21-37.

González, L. R. (2002b). Heredarás el bronce. Incas y metalurgia en el Sur del valle de Yocavil. Intersecciones en Antropología, 3, 55-68.

González, L. R. (2004). Bronces sin nombre. La metalurgia prehispánica en el Norte Argentino. Buenos Aires: Fundación Ceppa.

González, L. R. (2010). Fuegos sagrados. El taller metalúrgico del sitio 15 de Rincón Chico (Catamarca, Argentina). Boletín del Museo Chileno de Arte Precolombino, 15, 47-62.

González, L. R. y Gluzman, G. (2009). Agarráme si puedes. Métodos de sujeción de crisoles en el taller metalúrgico prehispánico del sitio 15 de Rincón Chico. Anuario de Arqueología, 1, 139-152.

González, L. R. y Tarragó, M. (2004). Producción tecnológica e identidad durante el dominio incaico en el Noroeste Argentino. Boletín de Arqueología PUCP, 8, 191-207.

Gosselain, O. P. (1992). Bonfire of the enquiries. Pottery firing temperatures in archaeology: What for? Journal of Archaeological Science, 19(3), 243-259. https://doi.org/10.1016/0305-4403(92)90014-T

Grim, R. y Kulbicki, G. (1961). Montmorillonite: High temperature reactions and classification. The American Mineralogist, 46, 1329-1369.

Hammer, F. y Hammer, J. (1993). The potter's dictionary of materials and techniques (Third). Philadelphia, PA: University of Pennsylvania Press.

Hein, A., Gluzman, G. y Kilikoglou, V. (2018). Pre-Columbian metallurgy - Evidence of pyrotechnical ceramics from Rincón Chico, Northwestern Argentina (Andes). Journal of Archaeological Science: Reports, 21, 1163-1170. https://doi.org/10.1016/j.jasrep.2017.12.031

Hein, A., Gluzman, G. y Kilikoglou, V. (2015). Pre-columbian pyrotechnical ceramics from Argentina [Poster]. 13th European Meeting on Ancient Ceramics, Athens, Grecia.

Hein, A., Kilikoglou, V. y Kassianidou, V. (2007). Chemical and mineralogical examination of metallurgical ceramics from a Late Bronze Age copper smelting site in Cyprus. Journal of Archaeological Science, 34(1), 141-154. https://doi.org/10.1016/j.jas.2006.04.005

Hein, A., Müller, N. S., Day, P. M. y Kilikoglou, V. (2008). Thermal conductivity of archaeological ceramics: The effect of inclusions, porosity and firing temperature. Thermochimica Acta, 480(1), 35-42. https://doi.org/10.1016/j.tca.2008.09.012

Horta, H. (2008). Insignias para la frente de los nobles Incas: Una aproximación etnohistórica- arqueológica al principio de la dualidad. En González, P. y Bray, T. (Eds.). Lenguajes visuales de los Incas (pp. 71-89). Oxford: Archaeopress.

Horta, H. (2016). The chin adornment of the highland lords as a symbol of historical continuity and ethnic emblem in the Southern Andes (500-1600 AD.). Chungara. Revista de Antropología Chilena, 48(3).

Housse, R. (1960). Cementerios indígenas en el centro de Chile. Revista Universitaria, 23, 47-56. 
Karageorghis, V. y Kassianidou, V. (1999). Metalworking and Recycling in Late Bronze Age Cyprus the Evidence from Kition. Oxford Journal of Archaeology, 18(2), 171-188. https://doi.org/10.1111/14680092.00078

Koutsopoulos, S. (2002). Synthesis and characterization of hydroxyapatite crystals: A review study on the analytical methods. Journal of Biomedical Materials Research, 62(4), 600-612. https://doi.org/10.1002/ jbm. 10280

Latcham, R. (1928). La alfarería de Chile central. En La alfarería indigena chilena. Santiago: Sociedad Imprenta y Litografía Universo.

Latorre, E. (2006). Trabajo de metales tempranos en Chile Central. Werken, 8, 77-90.

Latorre, E. (2009). De adornos y herramientas nacidos del fuego: Una caracterización del trabajo de metales en la cultura Diaguita (c.a. 900-1536 d.C.). Memoria para optar al título de Arqueólogo. Facultad de Ciencias Sociales, Departamento de Antropología, Universidad de Chile. Repositorio Académico de la Universidad de Chile. http://repositorio.uchile.cl/handle/2250/106209

Latorre, E. y López, P. (2011). Los metales en la cultura Diaguita chilena metodológica e interpretativa. Intersecciones en Antropología, 12, 319-332.

Maggetti, M. (1982). Phase analysis and its significance for technology and origin. En Olin. J. S. y Franklin, A. (Eds.). Archaeological ceramics (pp. 121-134). Washington DC: Smithsonian Institution Press.

Maniatis, Y. y Tite, M. S. (1981). Technological examination of Neolithic-Bronze Age pottery from central and southeast Europe and from the Near East. Journal of Archaeological Science, 8(1), 59-76. https://doi. org/10.1016/0305-4403(81)90012-1

Maritan, L., Mazzoli, C., Nodari, L. y Russo, U. (2005). Second Iron Age grey pottery from Este (northeastern Italy): Study of provenance and technology. Applied Clay Science, 29(1), 31-44. https://doi. org/10.1016/j.clay.2004.09.003

Martínez, A. (2011). Reevaluación del sitio Cerro la Cruz. Su función en las estrategias de dominio incaico en el curso medio del Aconcagua. Memoria para optar al título de Arqueólogo. Facultad de Ciencias Sociales, Departamento de Antropología, Universidad de Chile]. Repositorio Académico de la Universidad de Chile. http://repositorio.uchile.cl/handle/2250/106350

Martínez, A. (2012). Reevaluación del sitio cerro La Cruz dentro de las estrategias de dominio incaico en el curso medio del Aconcagua. En Actas del XVIII Congreso Nacional de Arqueología Chilena, Valparaíso 2009 (pp. 433-440). Sociedad Chilena de Arqueología.

Martinón-Torres, M., Rehren, T., Thomas, N. y Mongiatti, A. (2009). Identifying materials, recipes and choices: Some suggestions for the study of archaeological cupels. En Archaeometallurgy in Europe (pp. 1-11). Milan: Associazione Italiana di Metallurgia (AIM).

Martinón-Torres, M., Thomas, N., Rehren, T. y Mongiatti, A. (2008). Some problems and potentials of the study of cupellation remains: The case of post-medieval Montbéliard, France. ArcheoSciences, 32(32), 59-70.

Mayer, E. F. (1986). Armas y herramientas de metal prehispánicas en Argentina y Chile. München: Verlag C.H. Beck. 
Medina, J. T. (1882). La conquista Incásica. En Los Aborigenes de Chile (pp. 319-426). Santiago: Fondo Histórico y Bibliográfico José Toribio Medina.

Mostny, G. (1947). Un cementerio incásico en Chile Central. Boletin del Museo Nacional de Historia Natural, 23, 17-39.

Mostny, G. (1959). La momia del Cerro El Plomo. Boletin del Museo Nacional de Historia Natural, 27(1).

Niemeyer, H. (1979). Dos tipos de crisoles prehispánicos del Norte Chico, Chile. Boletín del Museo Arqueológico de La Serena, 17, 92-109.

Niemeyer, H. (1986). El Imperio Inka. Actualización y perspectivas por registros arqueológicos y etnohistóricos. Comechingonia, Número Especial, 169-237.

Nodari, L., Marcuz, E., Maritan, L., Mazzoli, C. y Russo, U. (2007). Hematite nucleation and growth in the firing of carbonate-rich clay for pottery production. Journal of the European Ceramic Society, 27(16), 4665-4673. https://doi.org/10.1016/j.jeurceramsoc.2007.03.031

Odriozola, C. y Hurtado, V. (2005). Tecnología y producción de decoraciones cerámicas campaniformes con relleno de hueso en la cuenca media del Guadiana. En Avances en Arqueometría. Actas VI Congreso Ibérico de Arqueometría (pp. 71-79). Universitat de Girona.

Odriozola, C. y Hurtado, V. (2007). The manufacturing process of 3rd millennium BC bone based incrusted pottery decoration from the Middle Guadiana river basin (Badajoz, Spain). Journal of Archaeological Science, 34(11), 1794-1803. https://doi.org/10.1016/j.jas.2006.12.021

Odriozola, C. y Martínez-Blanes, J. M. (2007). Estimate of firing temperatures through bone-based chalcolithic decorated pottery. Journal of Thermal Analysis and Calorimetry, 87(1), 135-141. https://doi. org/10.1007/s10973-006-7833-6

Ohya, Y. y Takahashi, T. (1999). Acoustic Emission from a Porcelain Body during Cooling. Communications of the American Ceramic Society, 82(2), 445-448.

Orton, C., Tyers, P. y Vince, A. (1997). La cerámica en Arqueología (R. Barceló y J. A. Barceló, Trads.). Barcelona: Crítica, Grijalbo Mondadori S.A.

Pavlovic, D. (2010). Informe preliminar salvataje sitio arqueológico Los Nogales comuna de San Esteban provincia de Los Andes V región de Valparaíso. Informe de salvataje arqueológico inédito, Proyecto Fondecyt 1090680. Ms.

Pavlovic, D., Sánchez, R., Pascual, D. y Martínez, A. Rituales colectivos y dinámicas de interacción. Sociedades segmentarias y el Tawantinsuyu en el Collasuyu Meridional. En Hayashida, F. y Troncoso, A. (Eds.). Rethinking the Inka Empire: New Perspectives from Collasuyu. Austin,TX: University of Texas Press (en prensa).

Pavlovic, D., Sánchez, R., Pascual, D., Martínez, A., Cortés, C., Dávila, C. y La Mura, N. (2019). Rituales de la vida y de la muerte: Dinámicas de interacción entre el Tawantinsuyu y las poblaciones locales en la cuenca del Maipo-Mapocho, Chile central. Estudios Atacameños. Arqueología y Antropología Surandinas, 63, 43-80. https://doi.org/10.22199/issn.0718-1043-2019-0022

Pavlovic, D., Troncoso, A., González, P. y Sánchez, R. (2004). Por cerros, valles y rinconadas: Investigaciones arqueológicas sistemáticas en el valle del Putaendo, cuenca superior del río Aconcagua. Chungara. Revista de Antropología Chilena, 36, 847-860. https://doi.org/10.4067/S0717-73562004000400025 
Pavlovic, D., Troncoso, A., Sánchez, R. y Pascual, D. (2012). Un tigre en el valle. Vialidad, arquitectura y ritualidad incaica en la cuenca superior del río Aconcagua. Chungara. Revista de Antropología Chilena, 44(4), 551-570.

Pifferetti, A. (2004). Las cucharas de colada por el fondo en la metalurgia prehispánica. En Actas del Congreso CONAMET/SAM 2004. https://elcrisoluspt.files.wordpress.com/2008/09/crisoles.pdf

Plaza, M. T. (2010). Estudio sobre la metalurgia Incaica en Chile Central durante el Periodo Alfarero Tardio. Memoria para optar al título de Arqueólogo. Departamento de Antropología, Universidad de Chile. Repositorio Académico de la Universidad de Chile. http://repositorio.uchile.cl/handle/2250/106270

Plaza, M. T. (2013). Metallurgical traditions under Inka rule: A technological study of metals and ceramics from the Aconcagua Valley in Central Chile. Dissertation submitted in partial fulfilment of the requirements for the degree of MSc in Technology and Analysis of Archaeological Materials. UCL Institute of Archaeology, University College London.

Plaza, M. T. y Martinón-Torres, M. (2015). Metallurgical traditions under Inka rule: A technological study of metals and technical ceramics from the Aconcagua Valley, Central Chile. Journal of Archaeological Science, 54, 86-98. https://doi.org/10.1016/j.jas.2014.11.029

Pradell, T., González, L. R. y Gluzman, G. (2010). Estudios técnicos de materiales refractarios del Noroeste Argentino. En La arqueometría en Argentina y Latinoamérica (pp. 85-90). Editorial de la Facultad de Filosofía y Humanidades. Córdoba, Argentina: Universidad de Córdoba.

Quinn, P. (2013). Ceramic Petrography: The Interpretation of Archaeological Pottery and Related Artefacts in Thin Section. Oxford: Archaeopress.

Raffino, R., Iturriza, R., Iácona, A., Capparelli, A., Gobbo, D., Montes, V. y Vázquez, R. (1996). Quillay: Centro metalurgico inka en el noroeste argentino. Tawantinsuyu, 2, 59-69.

Rasmussen, K. L., De La Fuente, G. A., Bond, A. D., Mathiesen, K. K. y Vera, S. D. (2012). Pottery firing temperatures: A new method for determining the firing temperature of ceramics and burnt clay. Journal of Archaeological Science, 39(6), 1705-1716. https://doi.org/10.1016/j.jas.2012.01.008

Reimer, P. J., Bard, E., Bayliss, A., Beck, J. W., Blackwell, P. G., Ramsey, C. B., Buck, C. E., Cheng, H., Edwards, R. L., Friedrich, M., Grootes, P. M., Guilderson, T. P., Haflidason, H., Hajdas, I., Hatté, C., Heaton, T. J., Hoffmann, D. L., Hogg, A. G., Hughen, K. A., ... Plicht, J. van der. (2013). IntCal13 and Marine13 Radiocarbon Age Calibration Curves 0-50,000 Years cal BP. Radiocarbon, 55(4), 1869-1887.

Rice, P. (2005). Pottery Analysis. A sourcebook [1987]. Chicago, IL: University of Chicago Press.

Rivas, P. y Ocampo, C. (1997). Informe preliminar de las excavaciones de salvataje y de la inspección arqueológica en el fundo Santa Augusta de Quintay, V región. En Actas del II Congreso Chileno de Antropologí, Valdivia 1995, 2 (pp. 818-835). Colegio de Antropólogos de Chile.

Rivera-Muñoz, E. (2011). Hydroxyapatite based materials: Synthesis and characterization. En Fazel-Rezai, R. (Ed.). Biomedical Engineering: Frontiers and Challenges (pp. 75-98). Rijeka: IntechOpen.

Rodríguez, A. y González, C. (2000). Asentamiento humano con ocupaciones alfareras en torno a una piedra tacita. Montenegro, Chile Central. En Actas del XIV Congreso Nacional de Arqueología Chilena, Copiapó 1997, 2 (pp. 119-146). Editores Tamarugal. 
Rodríguez, A., Morales, R., González, C. y Jackson, D. (1993). Cerro La Cruz: Un enclave económico administrativo incaico, curso medio del Aconcagua (Chile Central). En Actas del XII Congreso Nacional de Arqueología Chilena, Temuco 1991, 2 (pp. 201-221). Sociedad Chilena de Arqueología.

Salazar, D. y Salinas, H. (2008). Tradición y transformaciones en la organización de los sistemas de producción mineros en el norte de Chile prehispánico: San José del Abra, siglos I al XVI d.C. En Cruz, P. y Vacher, J.-J. (Eds.). Mina y metalurgia en los Andes del Sur desde la época prehispánica hasta el siglo XVII. Lima: Instituto Francés de Estudios Andinos.

Sánchez, R. (2002). El Tawantinsuyu Salvaje en el Finis Terrae Australis (Chile Central). Revista Chilena de Antropologia, 16, 87-127.

Sánchez, R. (2004). El Tawantinsuyu en Aconcagua (Chile Central). Chungara. Revista de Antropología Chilena, 36(2), 325-336. https://doi.org/10.4067/S0717-73562004000200007

Schiegl, S., Goldberg, P., Pfretzschner, H. U. y Conrad, N. (2003). Paleolithic burnt bone horizons from the Swabian Jura: Distinguishing between in situ fireplaces and dumping areas. Areas Geoarchaeology: An International Journal, 18(5), 541-565.

Schobinger, J. (1995). Aconcagua. Un enterratorio incaico a 5.300 m de altura. Mendoza: Inca Editorial.

Schobinger, J., Ampuero, M. y Guercio, E. (2001). Descripción de las estatuillas asociadas al fardo funerario hallado en el Cerro Aconcagua. En Schobinger, J. (Ed.). El santuario incaico del cerro Aconcagua (pp. 266280). Mendoza: EDIUNC Universidad Nacional de Cuyo.

Sernageomin (2003). Mapa geológico de Chile: Versión digital. Publicación Geológica Digital, 4, 1-25.

Stehberg, R. (1975). Diccionario de sitios arqueológicos de Chile central. Publicación Ocasional del Museo Nacional de Historia Natural de Santiago, 17, 1-96.

Stehberg, R. (1976). La Fortaleza de Chena y su relación con la ocupación incaica de Chile Central. Publicación Ocasional del Museo Nacional de Historia Natural de Santiago, 23, 1-37.

Stehberg, R. (1977). Reflexiones acerca de la fortaleza Inca de Chena. Revista de Educación, 62, 46-51.

Stehberg, R. y Sotomayor, G. (1999). Cabis, guacas-fortalezas y el control incaico del valle de Aconcagua. Estudios Atacameños, 18, 237-248.

Stilborg, O. (2001). Temper for the sake of coherence: Analyses of bone- and chaff-tempered ceramics from Iron Age Scandinavia. European Journal of Archaeology, 4(3), 398-404. https://oi.org/10.1179/ eja.2001.4.3.398

Tite, M. S., Freestone, I., Meeks, D. y Bimson, M. (1982). The use of scanning electron microscopy in the technological examination of ancient ceramics. En Olin, J. S. y Franklin, A. (Eds.). Archaeological ceramics (pp. 109-120). Washington, DC: Smithsonian Institution Press.

Troncoso, A., Pavlovic, D., Acuto, F., Sánchez, R. y González, C. (2012). Complejo arquitectónico Cerro Mercachas: Arquitectura y ritualidad incaica en Chile Central. Revista Española de la Antropología Americana, 42(2), 293-319.

Walter, T., Paine, R. y Horni, H. (2004). Histological examination of bone-tempered pottery from mission Espiritu Santo (41VT11), Victoria County, Texas. Journal of Archaeological Science, 31, 393-398. 
White, H. (2010). Legge's Mount, The Tower of London, London. Scientific examination of the cupels. Technology Report. London: English Heritage.

Wolf, S. (2002). Estimation of the Production Parameters of Very Large Medieval Bricks from St. Urban, Switzerland. Archaeometry, 44(1), 37-65. https://doi.org/10.1111/1475-4754.00042

Yanik, G., Bozer, R., Çeken, M., Esenli, F. y Gocmez, H. (2012). The characterization of medieval ceramics excavated from the Eğirdir Caravanserai (Turkey). Ceramics - Silikáty, 56(3), 261-268.

Zori, C. (2018). Inca mining and metal production. En Alconini, S. y Covey, A. (Eds.). The Oxford Handbook of The Incas (pp. 375-393). New York, NY: Oxford University Press.

Zori, C. (2019). Extracting Insights from Prehistoric Andean Metallurgy: Political Organization, Interregional Connections, and Ritual Meanings. Journal of Archaeological Research, 1-56. https://doi.org/10.1007/ s10814-019-09128-7

Zori, C., Tropper, P. y Scott, D. (2012). Copper production in late prehispanic northern Chile. Journal of Archaeological Science, 40(2), 1165-1175. https://doi.org/10.1016/j.jas.2012.09.012

\section{Anexos}

Anexo 1. Minerales identificados en la XRD. Pl- plagioclasa; Ksf- feldespatos de potasio. Se destacan en negrita los minerales de arcilla (modificado de Plaza y Martinón-Torres 2015, tabla 3).

\begin{tabular}{|c|c|c|}
\hline \multicolumn{3}{|c|}{ Minerales identificados por Difracción de Rayos-x (XRD) } \\
\hline Mineral & Fórmula ideal & Muestras \\
\hline Cuarzo & $\mathrm{SiO}_{2}$ & R1-R2-R3-R4 \\
\hline Gehlenita & $\mathrm{Ca}_{2} \mathrm{Al}(\mathrm{AlSi}) \mathrm{O}_{7}$ & R1-R2-R3-R4 \\
\hline Calcita & $\mathrm{CaCO}_{3}$ & R1-R2-R3-R4 \\
\hline Hidroxiapatita (HAp) & $\mathrm{Ca}_{5}\left(\mathrm{PO}_{4}\right)_{3}(\mathrm{OH})$ & $\mathrm{R} 1-\mathrm{R} 2$ \\
\hline Montmorillonita & $\mathrm{Al},[\mathrm{Na}, \mathrm{Mg}])\left(\mathrm{Si}_{2} \mathrm{O}_{5}\right)_{2}(\mathrm{OH})$ & R1-R2 \\
\hline Andesina (Pl) & $(\mathrm{Na}, \mathrm{Ca})(\mathrm{Si}, \mathrm{Al})_{4} \mathrm{O}_{8}$ & R1-R2-R4 \\
\hline Enstatita & $\mathrm{Mg}_{2} \mathrm{Si}_{2} \mathrm{O}_{6}$ & R1-R2-R4 \\
\hline Diópsido & $\mathrm{CaMgSi}_{2} \mathrm{O}_{6}$ & $\mathrm{R} 1-\mathrm{R} 2-\mathrm{R} 4$ \\
\hline Anortita (Pl) & $\mathrm{CaAl}_{2} \mathrm{Si}_{2} \mathrm{O}_{8}$ & R1-R3 \\
\hline Magnetita & $\mathrm{Fe}_{3} \mathrm{O}_{4}$ & R1-R3-R4 \\
\hline Cristobalita & $\mathrm{SiO}_{2}$ & R3-R4 \\
\hline Espinela & $\mathrm{MgAl}_{2} \mathrm{O}_{4}$ & R3-R4 \\
\hline Oligoclasa (Pl) & $(\mathrm{Na}, \mathrm{Ca})(\mathrm{Si}, \mathrm{Al})_{4} \mathrm{O}_{8}$ & R1 \\
\hline Albita (Pl) & $\mathrm{NaAlSi}_{3} \mathrm{O}_{8}$ & $\mathrm{R} 2$ \\
\hline Hematita & $\mathrm{Fe}_{2} \mathrm{O}_{3}$ & $\mathrm{R} 2$ \\
\hline Sanidina (Kfs) & $(\mathrm{K}, \mathrm{Na})(\mathrm{Si}, \mathrm{Al})_{4} \mathrm{O}_{8}$ & $\mathrm{R} 2$ \\
\hline Hercinita & $\mathrm{Fe}_{2} \mathrm{Al}_{2} \mathrm{O}_{4}$ & $\mathrm{R} 4$ \\
\hline Sauconita & $\left(\mathrm{NaZn}(\mathrm{SiAl})_{2} \mathrm{O}_{5}(\mathrm{OH})\left(\mathrm{H}_{2} \mathrm{O}\right)_{2}\right.$ & $\mathrm{R} 4$ \\
\hline
\end{tabular}

Nota: Minerales buscados, pero no encontrados: clorita, glauconita, illita, vermiculita, caolinita, whitlockita, mullita, tridimita, fayalita y hematita. 
Anexo 2. Detalle del volumen y potencial contenido de metal en crisoles.

\begin{tabular}{|c|c|c|c|c|c|}
\hline & Sitio & $\begin{array}{l}\text { Profundidad } \\
\text { interna }(\mathrm{mm})\end{array}$ & $\begin{array}{c}\text { Diámetro } \\
\text { máximo }(\mathrm{mm})\end{array}$ & $\begin{array}{c}\text { Volumen aprox. } \\
(\mathrm{cm} 3)\end{array}$ & $\begin{array}{c}\text { Contenido de } \\
\text { metal aprox. }(\mathrm{kg})\end{array}$ \\
\hline 1 & Barrealito 18842 & 55 & 76 & 166 & 1,5 \\
\hline 2 & Barrealito 18895 & 60 & 105 & 335 & 3,0 \\
\hline 3 & Pachimoco 18869 & 28 & 55 & 80 & 0,7 \\
\hline 4 & Carrizalillo Grande & 88 & 120 & 294 & 2,6 \\
\hline 5 & Quillay & 48 & 106 & 230 & 2,0 \\
\hline 6 & Rincón Chico 15 - 533 & 48 & 96 & 220 & 2,5 \\
\hline 7 & Los Nogales $\mathrm{N}^{\circ} 1$ & 41 & 90 & 104 & 0,9 \\
\hline 8 & Los Nogales N³ (R4) & 42 & 75 & 80 & 0,7 \\
\hline \multirow[t]{4}{*}{9} & Los Nogales N4 (R3) & 26.5 & 102 & 83 & 0,7 \\
\hline & Promedio & 48,5 & 91,7 & 176,9 & 1,6 \\
\hline & Máximo & 88 & 120 & 335 & 3,0 \\
\hline & Minimo & 26,5 & 55 & 80 & 0,7 \\
\hline
\end{tabular}

Nota: Referencias: 1 y 2- Debenedetti, 1917; 3- L. R. González, 1997; 4- Niemeyer, 1979; 5- Raffino et al., 1996; 6: L. R. González, 2010. 